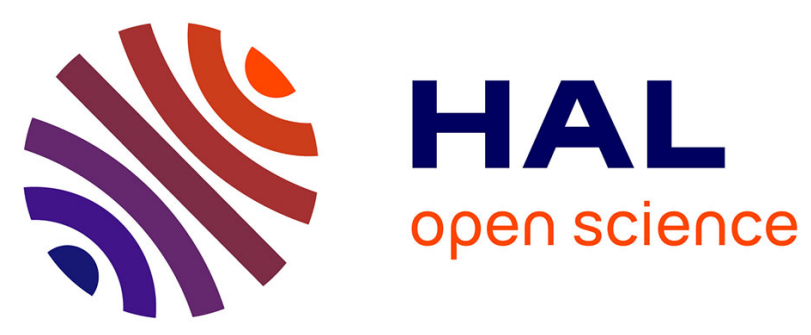

\title{
Myostatin deficiency is associated with lipidomic abnormalities in skeletal muscles
}

Narjes Baati, Christine Coudray, Gilles Fouret, Barbara Vernus, Benedicte

Goustard, Jérôme Lecomte, Véronique Blanquet, Laetitia Magnol, Anne

Bonnieu, Christelle Ramonatxo

\section{To cite this version:}

Narjes Baati, Christine Coudray, Gilles Fouret, Barbara Vernus, Benedicte Goustard, et al.. Myostatin deficiency is associated with lipidomic abnormalities in skeletal muscles. Biochimica et Biophysica Acta Molecular and Cell Biology of Lipids, 2017, 1862 (10 - part A), pp.1044-1055. 10.1016/j.bbalip.2017.06.017 . hal-01605145

\section{HAL Id: hal-01605145 \\ https://hal.science/hal-01605145}

Submitted on 26 May 2020

HAL is a multi-disciplinary open access archive for the deposit and dissemination of scientific research documents, whether they are published or not. The documents may come from teaching and research institutions in France or abroad, or from public or private research centers.
L'archive ouverte pluridisciplinaire HAL, est destinée au dépôt et à la diffusion de documents scientifiques de niveau recherche, publiés ou non, émanant des établissements d'enseignement et de recherche français ou étrangers, des laboratoires publics ou privés.

\section{(c)(1)}

Distributed under a Creative Commons Attribution| 4.0 International License 


\section{Accepted Manuscript}

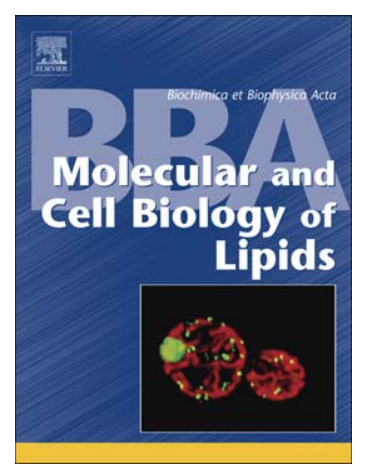

Myostatin deficiency is associated with lipidomic abnormalities in skeletal muscles

Narjes Baati, Christine Feillet-Coudray, Gilles Fouret, Barbara Vernus, Bénédicte Goustard, Charles Coudray, Jérome Lecomte, Véronique Blanquet, Laetitia Magnol, Anne Bonnieu, Christelle Koechlin-Ramonatxo

PII: $\quad$ S1388-1981(17)30121-X

DOI: $\quad$ doi: $10.1016 /$ j.bbalip.2017.06.017

Reference: $\quad$ BBAMCB 58173

To appear in: $\quad B B A-$ Molecular and Cell Biology of Lipids

Received date: 12 December 2016

Revised date: $\quad 19$ June 2017

Accepted date: 29 June 2017

Please cite this article as: Narjes Baati, Christine Feillet-Coudray, Gilles Fouret, Barbara Vernus, Bénédicte Goustard, Charles Coudray, Jérome Lecomte, Véronique Blanquet, Laetitia Magnol, Anne Bonnieu, Christelle Koechlin-Ramonatxo, Myostatin deficiency is associated with lipidomic abnormalities in skeletal muscles, BBA - Molecular and Cell Biology of Lipids (2017), doi:10.1016/j.bbalip.2017.06.017

This is a PDF file of an unedited manuscript that has been accepted for publication. As a service to our customers we are providing this early version of the manuscript. The manuscript will undergo copyediting, typesetting, and review of the resulting proof before it is published in its final form. Please note that during the production process errors may be discovered which could affect the content, and all legal disclaimers that apply to the journal pertain. 


\section{Myostatin deficiency is associated with lipidomic abnormalities in skeletal muscles}

Narjes Baati ${ }^{1}$, Christine Feillet-Coudray ${ }^{1}$, Gilles Fouret $^{1}$, Barbara Vernus ${ }^{1}$, Bénédicte Goustard ${ }^{1}$, Charles Coudray ${ }^{1}$, Jérome Lecomte ${ }^{2}$, Véronique Blanquet ${ }^{3}$, Laetitia Magnol ${ }^{3}$, Anne Bonnieu ${ }^{\text {1a }} \&$ Christelle Koechlin-Ramonatxo ${ }^{1 a^{*}}$

1 INRA, UMR866 Dynamique Musculaire Et Métabolisme, Université Montpellier, 34000 Montpellier, France

2 CIRAD, UMR IATE, Montpellier F-34398, France

${ }^{3}$ INRA, UMR1061 Unité de Génétique Moléculaire Animale, 87060 Limoges, France

*Correspondance: Christelle Koechlin-Ramonatxo

INRA, UMR866 Dynamique Musculaire et Métabolisme, Université Montpellier, F-34060, Montpellier, France

Email: christelle.ramonatxo@umontpellier.fr

$$
\begin{aligned}
& \text { Tel: +3349961 } 2338 \\
& \text { Fax: +3346754 } 5694
\end{aligned}
$$

${ }^{a}$ These authors are co-senior authors

Running Headline: Myostatin deficiency and lipidome metabolism in skeletal muscles 


\section{Highlights}

Lipidomic abnormalities in hypertrophied muscle of mstn deficient mice

Unbalanced fatty acid composition in mstn deficient muscle: towards saturated profile

Impaired cardiolipin pathway in skeletal muscle with oxidative mitochondrial disorders

\section{Abbreviations}

ACC Acetyl-CoA carboxylase

Alcat1 ER-associated monolyso-CL acyltransferase

ATP Adenosin triphosphate

AU Arbitrary Unit

$\beta$-HAD beta-hydroxyacyl CoA dehydrogenase

CHL Cholesterol

CL Cardiolipin

CLS Cardiolipin synthase

COX Cytochrome c oxidase

CPT1 Carnitine palmitoyltransferase I

CS Citrate synthase

DAG 1,2-diacylglycerol

DMD Duchenne muscular dystrophy

EDL Extensor digitorum longus muscle

FA Fatty acid

FABP3 Fatty acid binding protein 3

FAS Fatty acid synthase

FAT/CD36 Fatty acid translocase

FATP1 Fatty acid transport proteins 1

FATP4 Fatty acid transport proteins 4

FFA Free fatty acid

IMF Intermyofibrillar

KO Knock-out

GLUT4 Glucose transporter-4

LPC Lysophosphatidylcholine

MAG Monoacylglecerol

MIM Mitochondrial import complex

Mstn Myostatin

MUFA Monounsaturated fatty acids

OXA The oxidase assembly translocase

PA Phosphatidic acid

PC Phosphatidylcholine

PCR Polymerase chain reaction
PE Phosphatidyletanolamine

PG Phosphatidylglycerol

PGC1- $\alpha$ Peroxisome proliferator-activated receptor gamma coactivator 1 alpha

PGPS Phosphatidylglycerolphosphate synthase

PI Phosphatidylinositol

PPAR- $\delta$ Peroxisome proliferator-activated

receptor delta

PS Phosphatidylserine

PTPMT1 Mitochondrial Phosphatase

PUFA Polyunsaturated fatty acids

Rf Retention factor

RQ Relative Quantity

SAM Sorting and assembly machinery of the outer membrane

SCD1 Stearoyl-CoA desaturase

SFA Saturated fatty acids

SM Sphingomyelin

TAM41 The translocator maintenance protein

TAZ Tafazzin

TCA Tricarboxylic acid cycle

TG Triglycerides

TGF- $\beta$ Transforming Growth Factor Beta

TIM22 Carrier translocase of the inner membrane

TIM23 Presequence translocase of the inner

membrane

TLC Thin layer chromatography

TOM Translocase of the outer membrane

Tub Tubulin

WT Wild Type 


\begin{abstract}
Myostatin (Mstn) deficiency leads to skeletal muscle overgrowth and Mstn inhibition is considered as a promising treatment for muscle-wasting disorders. Mstn gene deletion in mice also causes metabolic changes with decreased mitochondria content, disturbance in mitochondrial respiratory function and increased muscle fatigability. However the impact of MSTN deficiency on these metabolic changes is not fully elucidated. Here, we hypothesized that lack of MSTN will alter skeletal muscle membrane lipid composition in relation with pronounced alterations in muscle function and metabolism. Indeed, phospholipids and in particular cardiolipin mostly present in the inner mitochondrial membrane, play a crucial role in mitochondria function and oxidative phosphorylation process. We observed that Mstn KO muscle had reduced fat membrane transporter levels (FAT/CD36, FABP3, FATP1 and FATP4) associated with decreased lipid oxidative pathway (citrate synthase and $\beta$-HAD activities) and impaired lipogenesis (decreased triglyceride and free fatty acid content), indicating a role of mstn in muscle lipid metabolism. We further analysed phospholipid classes and fatty acid composition by chromatographic methods in muscle and mitochondrial membranes. Mstn KO mice showed increased levels of saturated and polyunsaturated fatty acids at the expense of monounsaturated fatty acids. We also demonstrated, in this phenotype, a reduction in cardiolipin proportion in mitochondrial membrane versus the proportion of others phospholipids, in relation with a decrease in the expression of phosphatidylglycerolphosphate synthase and cardiolipin synthase, enzymes involved in cardiolipin synthesis. These data illustrate the importance of lipids as a link by which MSTN deficiency can impact mitochondrial bioenergetics in skeletal muscle.
\end{abstract}

Key words: GDF-8, thin layer chromatography, delta-9 desaturase, neutral lipids, phospholipids 


\section{Introduction}

Myostatin (Mstn), a secreted growth factor and member of the TGF- $\beta$ superfamily, regulates levels of lean muscle mass and also body fat content in mice [1]. Inactivation of the Mstn gene in mice, or mutations in the bovine [2,3] ovine [4] and human Mstn [5] genes result in a similar phenotype of increased muscle growth. Thus, targeted inhibition of Mstn gene has been considered as a promising treatment for various muscle-wasting disorders $[6,7,8,9]$. In this case, strategies have been developed to treat muscle dystrophies, muscle wasting and myopathies by blocking the Myostatin/ActRIIB pathway. Many clinical trials are in process but results are associated with undesirable adverse effects[10]. Therefore, a better understanding of the mechanisms underlying the muscle phenotype in Mstn knock-out (KO) model is warranted that may ultimately improve treatments.

Indeed, beyond muscle hypertrophy, Mstn KO mice show a disturbed muscle function with loss of muscle strength and endurance in vivo or ex vivo accompanied with a decrease in mechanical performance, and ATP production during exercise $[11,12,13,14]$. In parallel, many other metabolic changes have been documented in Mstn KO muscle such as a decrease in mitochondrial content, disturbance in mitochondrial respiratory function with a decay in the respiratory control ratio in intermyofibrillar mitochondria, and a decline in porine activity $[11,13,15]$. In addition, a decrease of fatty acid translocase (FAT/CD36) level, a lipid transporter, and the citrate synthase (CS) activity, one of the main mitochondrial oxidative enzyme, associated with a lower peroxisome proliferatoractivated receptor gamma coactivator 1 alpha (PGC1- $\alpha$ ) expression has been observed $[15,16]$. Although it is clear that lack of MSTN impairs muscle oxidative metabolism and mitochondrial function, the underlying mechanisms by which this alteration occurs have not been fully elucidated.

It is known that muscle mitochondrial function and oxidative metabolism are both highly reliant on the lipid pathway. Indeed, fatty acids (FA) are the main substrate for ATP production in muscle via the $\beta$-oxidation pathway [17]. Entering muscle fibers from blood via different transporters, lipids are then oxidized to Acyl-CoA in the cytosol then to acylcarnitine before translocating through mitochondria membranes by carnitine palmitoyltransferase I and II. These substrates in turn are subjected to oxidation by beta-hydroxyacyl CoA dehydrogenase ( $\beta$-HAD) and CS to produce ATP. Lipogenesis encompasses the processes of fatty acid and triglyceride synthesis from glucose [18]. After glycolysis, pyruvate is produced from glucose which then enters mitochondria. Through the tricarboxylic acid cycle (TCA), pyruvate is converted to acetyl-CoA and exported to cytosol to be used as a precursor for lipid synthesis. Indeed, acetyl-CoA carboxylase (ACC) converts acetyl-CoA into malonyl-CoA, which finally activates synthesis of triglycerides, using the fatty acid synthase enzyme (FAS) [18]. In the case of high-fat diet, fatty acids are also stored as triglycerides.

In addition to their energetic role, lipids are crucial components of cell membranes, including mitochondrial membranes. Moreover, mitochondrial characteristics and function are largely dependent 
of FA and phospholipid composition [19]. For example, being the most abundant phospholipid in both the outer mitochondrial membrane and the inner mitochondrial membrane, phosphatidylcholine (PC) modulates skeletal muscle mitochondrial function [20]. Genetic studies in mice or humans with defects in coline kinase $\beta$, enzyme catalysing the synthesis of PC, demonstrate that reduction of mitochondrial membrane PC content induced enlarged mitochondria, reduced inner membrane potential and caused muscle weakness [20-23]. The proper lipid composition of the membranes is crucial for membrane-bound protein machineries to maintain optimal mitochondrial biogenesis and function. The recent review of Martensson et al., 2016 illustrated that phospoholipids affect outer (TOM complex, MIM, SAM) and inner (TIM23, TIM22 and OXA) membrane protein translocases and thus play a crucial role in mitochondrial protein import [24].The role of phospholipids on mitochondria protein is also highlighted by their impact on respiratory chain supercomplexes [24]. In these studies, one phospholipid, cardiolipin (CL) attracted scientific attention. Mostly present in the inner mitochondrial membrane, CL undergoes two main phases for its activity [24,25]. The first is its biosynthesis that takes place on the matrix face of the inner mitochondrial membranes, pathway catalysed by numerous and successive enzymes as Tam41, Pgs1, PTPMT1 and finally by CL synthase (also called Crd1), to form premature (nascent) CL. The second phase is the remodelling of its fatty acids, with recruitment of a new set of tissue-specific fatty acids, and its assembly into the inner membrane. Nascent CL is deactyled by CL deacylases/phospholipases to monolyso-CL which is reactylated principally by the taffazin to mature CL [19,25]. CL interacts with a number of inner mitochondrial membrane proteins, enzymes and metabolite carriers, such as the electron transport chain complexes involved in oxidative phosphorylation and ADP/ATP carriers, which optimize efficient electron/proton flux and hence, ATP synthesis [26]. CL is also involved in the $\beta$-oxidation of fatty acids, as a reduction of mature CL impairs skeletal muscle FA oxidation [27,28] and a positive correlation has been demonstrated between mitochondrial COX activity and CL content [29]. Patients with Barth Syndrome (a X-linked disorder resulting from mutations in the gene encoding for tafazzin) or mice models which lack mature CL, have shown exercise intolerance, cardiac and skeletal muscle dysfunction, mitochondrial dysfunction, ATP deficiency and premature mortality [30,31,32] In vitro, mitochondrial respiration has been shown to be impaired in inducible pluripotent stem cell (iPSC)derived human cardiomyocytes from Barth Syndrome patients [33]. Possible mechanisms for this disease-associated mitochondrial dysfunction include mitochondrial supercomplex destabilization [34], higher reduced levels of mitochondrial cardiolipin [35] and abnormal mitochondrial morphology [30]. Recently, Bashir et al., 2016 [36] found higher resting skeletal muscle [PCr]/[Pi] in children/adolescents and adults with Barth syndrome, suggesting that individuals with Barth syndrome rely on glycolytic metabolism to a greater extent than unaffected, age-matched controls, likely due to an impairment in fat oxidation. These findings highlight the crucial role that mitochondrial CL plays in skeletal muscle oxidative metabolism and mitochondria bioenergetics processes [26]. 
Due to energetic and structure function of fatty acids and phospholipids in muscle, we hypothesized that in MSTN deficient hypertrophied skeletal muscle, hence a change in the muscle and mitochondrial lipid composition could exist, in relation with metabolic and mitochondrial abnormalities observed in this phenotype. In this study, we evaluated the lipid profile of muscle and mitochondrial membranes from Mstn KO mice, and explored muscle lipid metabolism pathway. We demonstrated in MSTN deficient muscle a decrease of both lipogenesis and lipid oxidation associated with important modifications in the fatty acid composition of total muscle lipid profile. Interestingly, we also found that muscle mitochondrial proportion of cardiolipin is significantly decreased in Mstn KO mice correlating with the reduced gene expression of two enzymes involved in cardiolipin synthesis. These results reveal alterations of the phospholipid profile in skeletal muscle of Mstn KO mice. We suggest that this could be mechanism through which lack of MSTN impacts mitochondrial function. 


\section{Material and Methods}

\section{Animals}

Male Mstn KO mice (10 wk old) used in this study have been described previously and were generously provided by L. Grobet (Faculty of Veterinary Medicine, University of Liège, Belgium) [37]. These mice harbor a constitutive deletion of the third Mstn exon leading to the deletion of the entire mature $\mathrm{COOH}$-terminal region of MSTN and were therefore null for MSTN function. The mice were generated on a FVB/N-C57BL genetic background. WT $(n=20)$ and Mstn KO mice $(n=20)$ were produced from homozygous matings. Parental genotyping were determined by polymerase chain reaction analysis of tail DNA. Mice were fed ad libitum and kept under a 12:12-h light-dark cycle.

The experimental protocols of this study were handled in strict accordance with European directives (86/609/CEE) and approved by the Ethical Committee of Region Languedoc Roussillon (APAFIS\#2551-2015110311365663v2).

\section{Muscle preparation and sample}

Mice were weighed and killed by cervical elongation. Tibialis anterior, extensor digitorum longus (EDL), and quadriceps muscles were quickly excised and immediately placed in ice-cold buffer (100 mM KCl, $5 \mathrm{mM} \mathrm{MgSO} 4,5 \mathrm{mM}$ EDTA, and $50 \mathrm{mM}$ Tris. $\mathrm{HCl}, \mathrm{pH}$ 7.4) for total mitochondria extraction. Gastrocnemius was removed and then frozen in liquid nitrogen. Gastrocnemius was powdered to perform analysis of protein, mRNA expression and analysis of fatty acid and enzymatic activity measures.

\section{Mitochondria isolation}

Total mitochondria were fractionated by differential centrifugation as described previously [38]. Briefly, muscles were freed of connective tissues, minced, and homogenized with a Potter-Elvehjem homogenizer. Then, mitochondria were obtained from the initial pellet following a treatment with Subtilisin A $(0.25 \mathrm{mg} / \mathrm{g}$ wet muscle) and subsequent centrifugations at 800 and 9,000 g. Total mitochondria were resuspended in $100 \mathrm{mM} \mathrm{KCl}$ and $10 \mathrm{mM} \mathrm{MOPS}, \mathrm{pH}$ 7.4. Mitochondrial protein content was determined using the Bradford assay, and the yield was expressed as milligram of mitochondrial proteins per gram of muscle wet weight.

\section{Lipids extraction and thin layer chromatography (TLC)}

\section{Triglyceride (TG) and free fatty acids (FFA) content in muscle lipid extracts by TLC-densitometry}

Muscle lipids were extracted using a mixture of chloroform-methanol (2:1 by volume) in the presence of butylated hydroxytoluene $(50 \mathrm{mg} / \mathrm{l})$ according to [39]. The application of lipid extracts of 
muscle homogenate on silica gel 60 HPTLC plates $(250 \mu \mathrm{m}, 20 \times 10 \mathrm{~cm}$; Merck, Germany), pre-treated with $1.5 \%$ w/v boric acid in ethanol, was automatically performed on a 4-mm band width using a CAMAG ATS4 apparatus (Muttenz, Switzerland). Two developments were performed, first with pentane-chloroform-methanol (52:45:3, by volume) on 60-mm migration distance and second with pentane-diethyl ether ( $97: 3$ by volume) on 67-mm migration distance, which allowed the separation of neutral lipids. The scanning of the plates was carried out using a CAMAG TLC scanner 3 (Muttenz, Switzerland) operating in the reflectance mode. The plates were scanned at $550 \mathrm{~nm}$ after dipping in a solution of copper sulphate $640 \mathrm{mM}$ in $\mathrm{H} 3 \mathrm{PO} 41.18 \mathrm{M}$ and heating for $20 \mathrm{~min}$ at $180^{\circ} \mathrm{C}$. The 1 monoacylglycerol (MAG), 1,2- diacylglycerol (DAG) and 1,3-DAG, TG, cholesterol (CHL) and FFA contents were finally identified by comparing their retention factor (Rf) with authentic standards and were quantified using calibration curves of the same standards [40].

\section{FFA composition of muscle by gas chromatography}

Fatty acid methyl esters were prepared by incubation with acidified methanol, according to

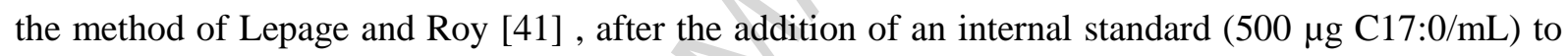
lipids in the Folch extract. Briefly, the methylation reagent was generated by mixing sulphuric acid (5\% v.v) with methanol (95\% v.v) and butylated hydroxytoluen as antioxidant (50 mg/L), and the sample was heated at $90^{\circ} \mathrm{C}$ for $45 \mathrm{~min}$ to get the fatty acid methyl esters. After addition of sodium bicarbonate, distilled water and hexane, the sample was vortexed, centrifuged, and the upper hexane layer was transferred to a glass vial, evaporated under a nitrogen stream at $37^{\circ} \mathrm{C}$, and dissolved in isooctane for gas chromatography analysis. Individual fatty acid methyl esters were identified according to the retention times of standards by gas liquid chromatography (Trace GC Ultra, Thermo Fisher Scientific, Courtaboeuf, France), with a Supelco Vax capillary column [30mx0.32mm idx $0.25 \mu \mathrm{m} \mathrm{df}$ ], an AS-3000 autosampler and flame-ionization detector (Thermo Electron Corporation, Thermo Fisher Scientific). The fatty acid methyl esters were quantified using the chromatographic peak area according to the internal standard method. The FA composition of total lipids and mitochondrial lipids were compared in terms of the percentage content of various fatty acids. The sum of the dimethylactals DMA16:0 and DMA18:0, the main plasmalogens were also quantified, as controls and showed limited proportion in skeletal muscles.

\section{Tissue desaturase indices and unsaturation index}

Since it is not possible to directly measure the activity of the enzymes that catalyze the desaturation and elongation reactions in the fatty acid metabolic pathways, results in animals have supported the use of surrogate measures of desaturase activity such as the use of desaturase indices [42]. These indices are based on the ratio of product to precursor of individual fatty acids. The desaturase indices were calculated as follows: $\Delta 9,[16: 1(\mathrm{n}-7) / 16: 0] ; \Delta 6,[18: 3(\mathrm{n}-6) / 18: 2(\mathrm{n}-6)]$; and $\Delta 5,[20: 4(\mathrm{n}-6) / 20: 3(\mathrm{n}-$ 
6)]. The unsaturation index (UI) was calculated from the relative percentage of each type of mono- and polyunsaturated fatty acid multiplied for the number of double bonds present in the molecule [43].

\section{Phospholipid composition of muscle mitochondrial membrane by TLC-densitometry}

Muscle mitochondrial suspensions were extracted by a mixture of chloroform/methanol (2:1 by volume) according to [39] in the presence of $50 \mathrm{mg} / \mathrm{L}$ of butylated hydroxytoluene. Phosphorus was quantified on Folch extracts of mitochondrial suspensions in order to determine total phospholipid quantity as previously described [44]. The application of Folch extracts of muscle mitochondrial suspensions on silica gel 60 HPTLC plates $(250 \mu \mathrm{m}, 20 \times 10 \mathrm{~cm}$, Merck, Germany) pretreated with $2.3 \% \mathrm{w} / \mathrm{v}$ boric acid in ethanol, was automatically performed on a $4 \mathrm{~mm}$ band width using a CAMAG ATS4 apparatus (Muttenz, Switzerland). The development was performed with methanol/acetic acid/pentane/chloroform (15/10/30/45, by volume), which allowed the separation of phospholipids on a $60 \mathrm{~mm}$ total migration distance. The scanning of the plates was carried out using a CAMAG TLC scanner 3 (Muttenz, Switzerland), operating in the reflectance mode. The plates were scanned at 715 $\mathrm{nm}$ after dipping in a solution of Blue Spray (Sigma,France) (Blue Spray $/ \mathrm{H}_{2} \mathrm{SO}_{4} 4.2 \mathrm{M} /$ acetone, 1/2/3 by volume,) and heating for $3 \mathrm{mn}$ at $55^{\circ} \mathrm{C}$. The different classes of phospholipids (SM, LPC, PC, PI, PS, PE, PG, PA, CL) were identified by comparing their retention factor (Rf) to authentic standards and quantified using calibration curves of the same standards [45]. Results are expressed as percentage of nmol of phosphorus in total phospoholipids, and indicate for each phospholipid its proportion (\%) in the composition of mitochondrial membrane. We also estimate the mitochondria CL content expressing in $\mu \mathrm{moL}$ pf phosphorus in CL per mg of mitochondrial protein.

\section{Enzyme activity assays}

Lipids oxidation was evaluated by CS and $\beta$-HAD activities. CS activity was measured according to Srere et al., 1969 [46] : the activity of the enzyme was measured spectrophotometrically at $412 \mathrm{~nm}$ by following the yellow color of 5-thio-2-nitrobenzoic acid, which is generated from the reaction of 5,5'dithiobis-2-nitrobenzoic acid with the free -CoA liberated from the reaction of acetyl-CoA and oxaloacetate under citrate synthase action to synthesize citrate. $\beta$-HAD activity was measured according to [47]. The activity of the enzyme was measured spectrophotometrically at $340 \mathrm{~nm}$ by following the disappearance of NAD. The $\beta$-HAD converted the acetoacetyl-CoA in alcohol inversely $\beta$-oxidation reaction.

\section{Protein extraction and Western blot analysis}

$50 \mathrm{mg}$ gastrocnemius muscle powder was homogenized using an Potter-Elvehjem homogenizer Craig recrystallization tube homogenizer (KONTES GLASS CO, Sigma, VINELAND NJ) in an ice cold extraction buffer (20 mM HEPES, pH 7.4, 2 mM EGTA, $50 \mathrm{mM} \beta$-glycerophosphate, $1 \mathrm{mM}$ dithiothreitol, $1 \mathrm{mM} \mathrm{Na} \mathrm{VO}_{4}, 10 \%$ glycerol, $1 \%$ Triton $\mathrm{X}-100,10 \mu \mathrm{M}$ leupeptin, $5 \mu \mathrm{M}$ pepstatin $\mathrm{A}, 3$ $\mathrm{mM}$ benzamidine, $10 \mu \mathrm{g} / \mathrm{mL}$ aprotinin, and $1 \mathrm{mM}$ phenylmethylsulfonyl fluoride). Proteins were 
denatured by mixing with an equal volume of Leammli Buffer and the linearization was achieved by heating the samples for $5 \mathrm{~min}$ at $95^{\circ} \mathrm{C}$ Proteins $(50 \mu \mathrm{g})$ were separated on SDS-PAGE and then transferred (Tris-glycine 1x, ethanol 100\%, H2O) to a nitrocellulose membrane (nitrocellulose, 0.2 $\mu \mathrm{m}$, Bio-RAD, CAS\#9004-70-0) (90 minutes, 400mA). Membranes were blocked in (Tris-buffered saline) TBS1X/0.1\% Tween-20 containing either 5\% fat-free milk or 5\% BSA for 1 hour at room temperature.

Then, membranes were incubated overnight with primary antibody against, FAT/CD36, FATP1, FATP4, SCD1 (1/500; Santa Cruz Biotechnology, CA), FABP3, CLS (1/500; Abcam, Cambridge, UK), FAS (1/1000, Cell Signaling Technology 3180S, Danvers, MA), CS (1/1000; Genetex) and $\boldsymbol{\alpha}$-tubulin (1/5000; Sigma-Aldrich, St Louis, MO) in blocking buffer. After washes in TBS1X/0.1\% Tween-20 under gentle agitation, membrane was incubated for 1 hour with horseradish peroxidase-labelled antibody (Anti mouse NA931V,GE, UK, Anti Rabbit NA934V,GE, UK, AntiGoat, SC-2768, Santa Cruz Biotechnology, CA).

After further washes, antibody bound proteins were revealed using enhanced chemiluminescence detection reagents (ECL, ThermoScientific, Courtaboeuf, France). Signals detected with ChemiDoc ${ }^{\mathrm{TM}}$ Touch Imaging System instrument (Bio-RAD, 1.1.0.4, 732BR1121). $\alpha$ tubulin was used as loading reference. Gel band intensities in the membranes were measured using the Image Lab software (Version 5.2.1 for Windows 7).

\section{Quantification of mRNA expression by real time reverse transcription (RT-qPCR)}

Total RNAs were isolated from gastrocnemius muscle powder using the RNeasy Fibrous Tissue Mini Kit following the manufacturer's instructions (Qiagen, Venlo, The Netherlands). RNA concentration was determined by spectrophotometric analysis (Eppendorf AG, Hamburg, Germany), and purity was checked by the OD260nm/OD280nm absorption ratio (>1.7).

Reverse transcription reaction was performed with $1 \mu \mathrm{g}$ of total RNA using the TAKARA kit (TAKRR037A, PrimeScript RT reagent Kit, Perfect Real Time) according to the manufacturer's instructions. One-tenth of the cDNA was used in each polymerase chain reaction (PCR).

Quantitative PCR (qPCR) analysis was performed in a MiniOpticon detection system (BioRad, Hercules, CA) with $18 \mu \mathrm{L}$ of Mastermix (SYBR Premix Ex Taq II, Takara), 300nM of both forward and reverse primers, $2 \mu \mathrm{L}$ of diluted cDNA template and water to a final volume of $20 \mu \mathrm{L}$. The forward and reverse primers used to amplify genes are listed in Table 1. We used Cpt- 1 and Ppar- $\delta$ genes for lipid oxidation; Pgps for cardiolipin synthesis, Taz and Lcat1 for cardiolipin remodelling.

All PCRs were performed in duplicate using the following cycle parameters: $30 \mathrm{~s}$ at $98^{\circ} \mathrm{C}, 40$ cycles of $1 \mathrm{~s}$ at $95^{\circ} \mathrm{C}$ and $15 \mathrm{~s}$ at $60^{\circ} \mathrm{C}$. Relative mRNA levels were normalized to ribosomal protein ARP and $\alpha$ tubulin housekeeping gene levels, which were unaffected by treatments. Results are expressed using the comparative cycle threshold (CT) method to generate $\Delta \Delta \mathrm{CT}$ values. PCR amplification was 
performed with template dilutions ranging from $10^{1}$ to $10^{6}$ copies. Overall efficiencies (E) of PCR were calculated from the slopes of the standard curves according to the equation $E=\left[10^{(-1 / \text { slope })}\right]-1$. All PCR efficiencies were above 95\%. The relative abundance of each sample was then normalized according to the equation: Relative Quantity $=2^{-\square \square \mathrm{Ct}}[48]$.

\begin{tabular}{|c|c|c|}
\hline Role & Gene & Forward Primer (5'-3') \\
\hline Housekeeping & Arp & 5'-ACTGGTCTAGGACCCGAGAAG-3' \\
\hline Gene & $\alpha$-tubulin & 5'GTGGCCACGAGCATAGTTATT-3' \\
\hline \multirow{2}{*}{ Lipid oxidation } & Cpt1 & 5'AAGCGACCTTTGTGGTAGACA-3' \\
\hline & Ppar- $\delta$ & 5'GTCTGAGCGCAGATGGACT-3' \\
\hline $\begin{array}{c}\text { Cardiolipin } \\
\text { synthesis enzyme }\end{array}$ & Pgps & 5'CTCACGCTGATTGGCTCTC-3' \\
\hline Cardiolipin & Taz & 5'CCAGCCCATGTTTAACTGCT-3' \\
\hline Remodeling enzyme & Alcat1 & 5'ACACCTGCCCTCAACACAG-3' \\
\hline
\end{tabular}

Table 1. Primers used for real-time quantitative PCR

\section{Statistical analysis}

All data are presented as means \pm SEM. Data were compared between the two groups of mice WT and Mstn KO using an unpaired t-test or a Mann-Whitney rank sum test when normality was not obtained. The significance level was set at 0.05 . The data were analyzed using the statistical package Graphpad Prism version 6.02 for windows (GraphPad Software, La Jolla, California). 


\section{Results}

\section{Animals and muscle characteristics}

Consistent with the hypermuscular phenotype, at 10 weeks of age, Mstn KO mice displayed greater body and muscle (gastrocnemius, EDL, soleus) weights compared to their WT littermates (Table 2).

\begin{tabular}{crc}
\hline Weight & \multicolumn{1}{c}{ WT } & Mstn KO \\
\hline Body $(\mathbf{g})$ & $25.7 \pm 0.5$ & $34.1 \pm 0.3^{*}$ \\
EDL $(\mathbf{m g})$ & $9.8 \pm 0.2$ & $18.6 \pm 0.6^{* * *}$ \\
Gastrocnemius (mg) & $140.2 \pm 0.2$ & $259.9 \pm 0.4 * * *$ \\
Soleus (mg) & $7.5 \pm 0.2$ & $14.9 \pm 0.4 *$
\end{tabular}

Table 2. Body and muscle weights in WT and Mstn KO Mice .

Data are presented as means $\pm \mathrm{SEM} ; \mathrm{n}=20$ mice in each group. WT; wild type; KO, knockout; EDL. Extensor digitorum longus, $* \mathrm{P}<0.05$ and $* * * \mathrm{P}<0.001$ vs. WT.

\section{Decreased lipid oxidation in Mstn KO muscle}

We and others have recently shown that inhibition of Mstn represses muscle endurance and metabolic mitochondrial function $[13,15]$. As this metabolic phenotype is greatly dependent on lipids, we first investigated whether myostatin deletion would impact mitochondrial lipid oxidation in muscle.

Mitochondrial yield and CS quantity were significant reduced in mstn gastrocnemien muscles (Figure 1A and B) confirming the reduced mitochondrial pool in mstn KO mice $v s$ WT. The activity of isolated key mitochondrial enzymes, CS and $\beta$-HAD, was decreased in gastrocnemius muscle homogenates from KO compared to WT littermates (Figure 1C). Supporting the decrease of lipid oxidation, we found reduced mRNA level of Cpt1, a membrane mitochondrial lipid transporter (Figure 1D). Furthermore, mRNA levels of Ppar- $\delta$, a key transcription factor promoting oxidative metabolism is also markedly reduced in mstn deficient muscle (Figure 1D). Altogether, these data suggest that oxidative metabolism and lipid $\beta$-oxidation is down-regulated in the absence of myostatin. In agreement with these results, we observed decreased protein content of CD36, FABP3 (fatty acid binding protein 3), FATP1 and FATP4 (fatty acid transport proteins 1 and 4), all of which are involved in lipid membrane and cytosolic transport, in gastrocnemius muscle of $\mathrm{KO}$ mice compared to WT mice (Figures 2A, 2B). Inversely, we showed that protein involved in muscle glucose uptake, as hexokinase II (HKII) and glucose transporter type 4 (GLUT4) protein content were respectively significant increased or tended to be increased in mstn KO muscle in comparison with control group (Figure 3). 
A)

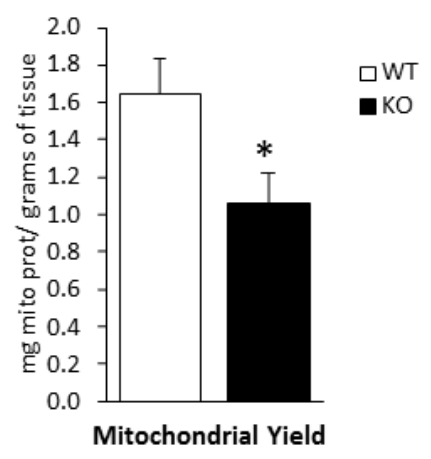

B)
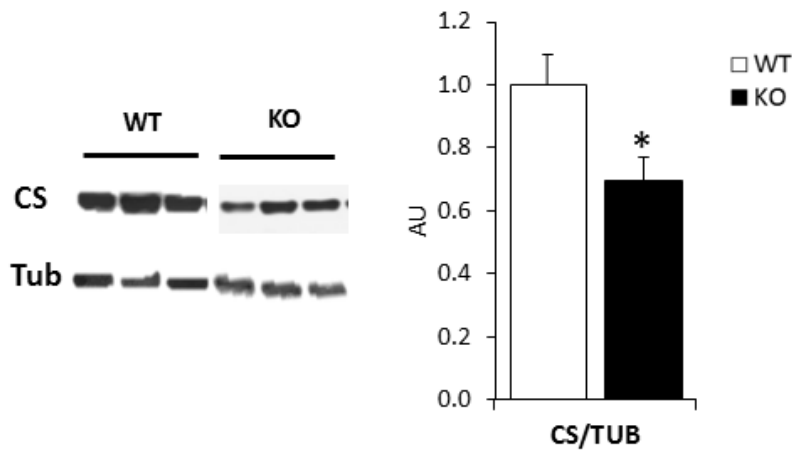

C)

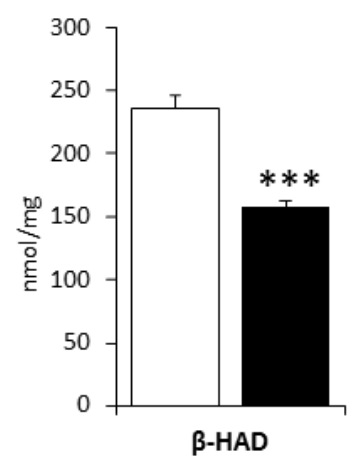

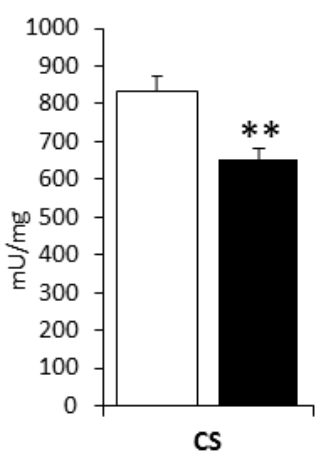

D)

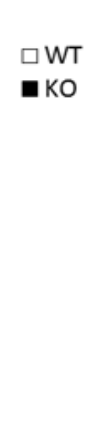

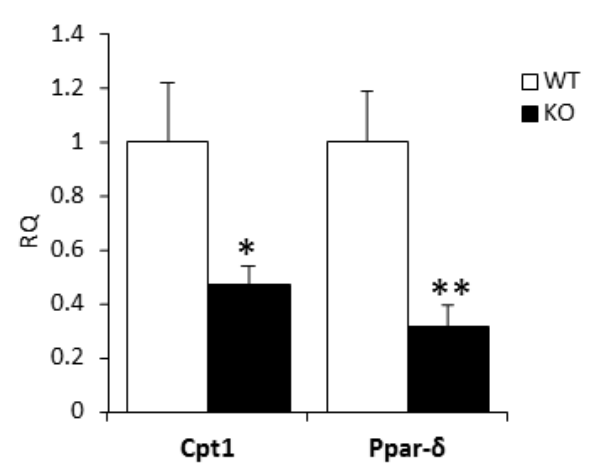

Figure 1: Markers of mitochondrial content and $\beta$-oxidation in WT and Mstn KO mice A) Mitochondrial yield in mixed muscle homogenates from WT (open bars) and mstn KO mice (filled bars). B) Citrate synthase quantity evaluated by Western blot in mstn KO muscle compared to WT muscle. A representative Western blot

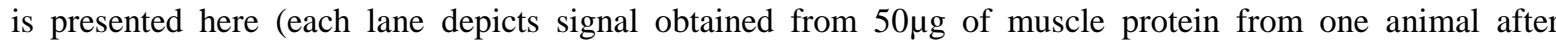
western-blot analysis) and quantification of CS protein levels expressed relative to $\alpha$-tubulin levels in gastrocnemius muscle from Mstn KO mice compared to WT mice. The ratio is expressed relative to control WT (arbitrary taken as 1). C) Enzymatic activities evaluated by spectrophotometry of $\beta$-HAD and citrate synthase in gastrocnemius muscle homogenates from WT (open bars) and mstn KO mice (filled bars). D/ Cpt1 and Ppar- $\delta$ gene expression evaluated by RT-PCR in WT and Mstn KO muscle. Values are shown as means \pm SEM. P-Values were calculated using the parametric test T-student, except for $\beta$-HAD and Ppar- $\delta\left({ }^{*} \mathrm{p}<0.05\right.$; $* * \mathrm{p}<0.01 ; * * * \mathrm{p}<0.001 v s \mathrm{WT}) \mathrm{mU} / \mathrm{mg}$ : units of activity per mg of total muscular protein. AU: Arbitrary Units.RQ: Relative Quantity. ( $\mathrm{n}=10$ per group).

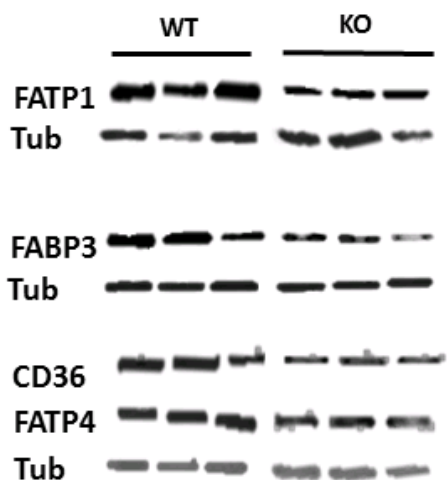

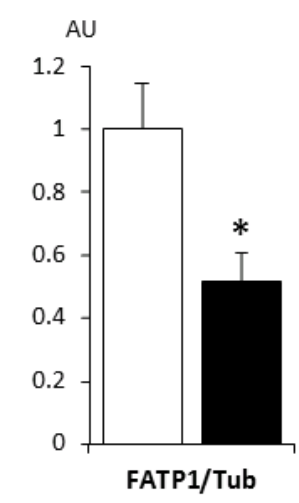
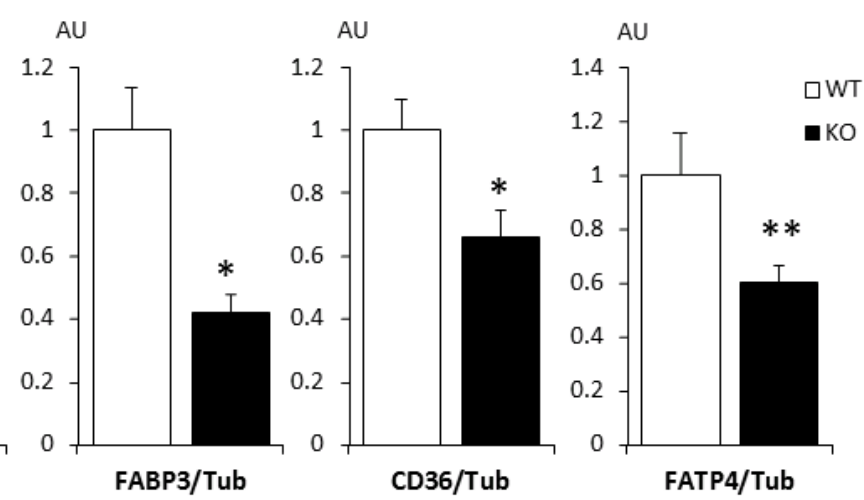

Figure 2: Lipid transporters in WT and Mstn KO mice A) Representative immunoblots showing protein expression levels of the lipid membrane and cytosolic transporters FATP1, FABP3, CD36 and FATP4 within

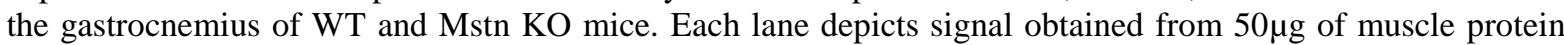
from one animal after western-blot analysis B) Quantifications of FATP1, FABP3, CD36 and FATP4 are normalized to $\alpha$-tubulin. The ratio is expressed relative to control WT (arbitrary taken as 1). Values are shown as means \pm SEM. P-Values were calculated using the parametric test T-student $\left({ }^{*} \mathrm{p}<0.05\right.$. $\left.{ }^{* *} \mathrm{p}<0.01\right)$. AU: Arbitrary Units. ( $\mathrm{n}=10$ per group). 

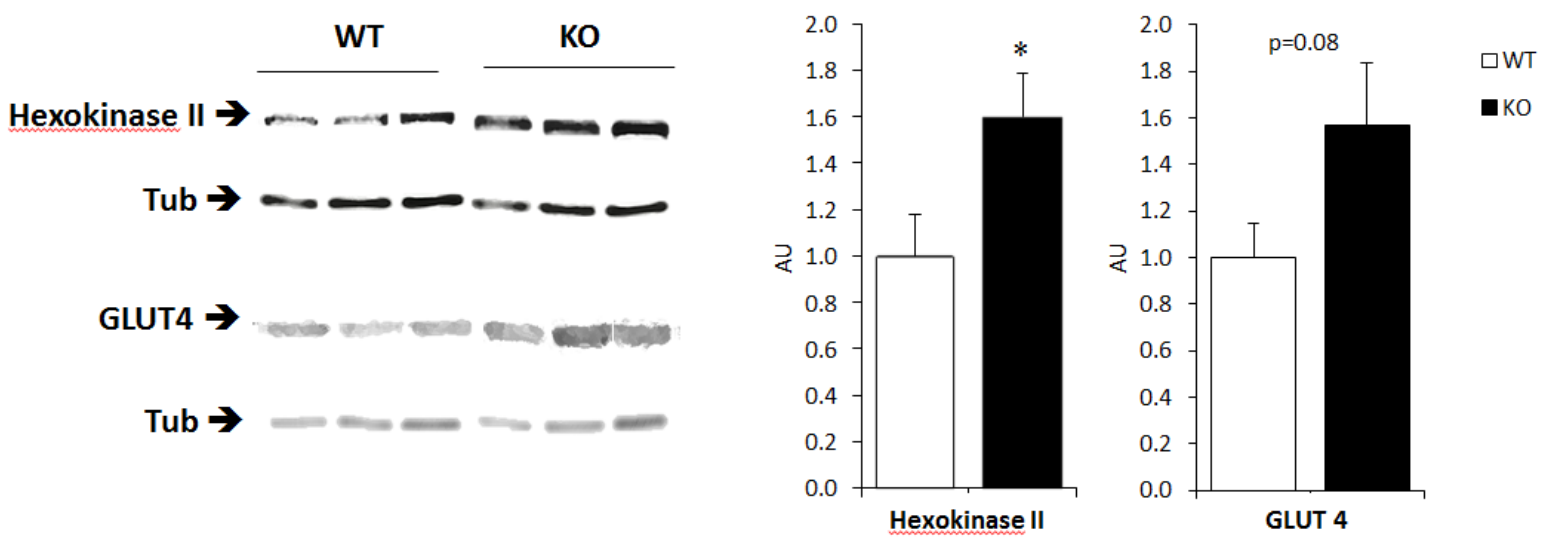

Figure 3: Glycolytic markers in WT and Mstn KO mice A) Representative immunoblots showing protein expression levels of the Hexokinase II and glucose transporter GLUT4 within the gastrocnemius of WT and

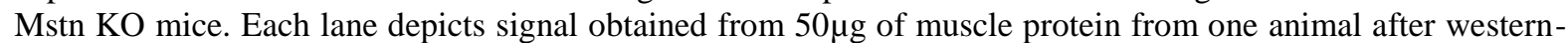
blot analysis B) Quantifications of hexokinase II and GLUT4 are normalized to $\alpha$-tubulin. The ratio is expressed relative to control WT (arbitrary taken as 1). Values are shown as means \pm SEM. P-Values were calculated using the parametric test T-student $(* \mathrm{p}<0.05)$. AU: Arbitrary Units. ( $\mathrm{n}=10$ per group).

\section{Decreased lipogenesis in Mstn KO muscles}

Since lipogenesis involves synthesis of fatty acids from excess carbohydrates leading to TG storage, we next tested whether MSTN deficiency altered this metabolic pathway. Western blot analysis showed that FAS levels were decreased in Mstn KO gastrocnemius compared to WT (Figure 4A). In agreement with this, we found that TG levels were 4-fold lower in Mstn KO mice compared with WT

(Figures $4 B, 4 C_{A}$ )
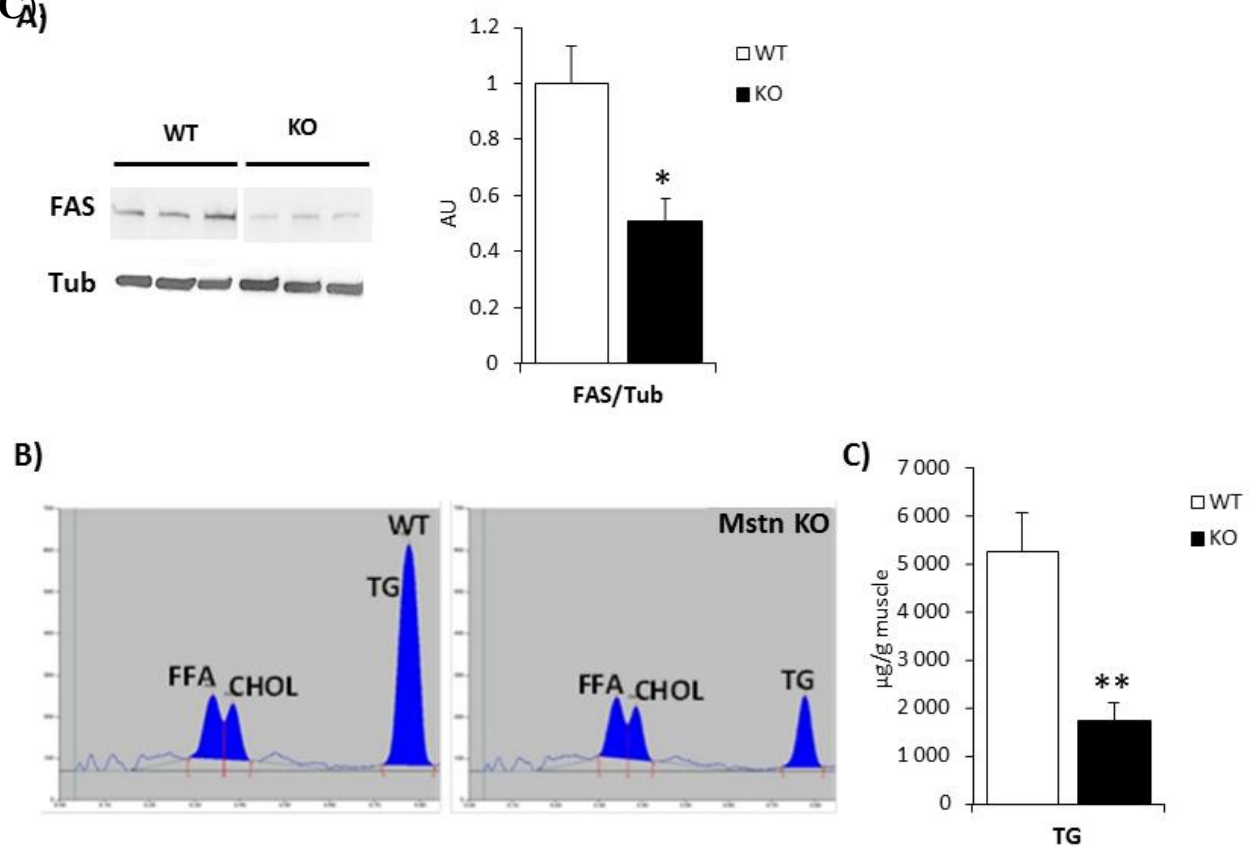

Figure 4: Lipogenesis markers in WT and Mstn KO mice A) Representative immunoblots showing protein expression levels and quantification of FAS evaluated by western blot (normalized to $\alpha$-tubulin) in Mstn KO gastrocnemius compared with WT ( $\mathrm{n}=10$ per group) B) Representative thin layer chromatrography analysis: the profile indicates the amounts of TG, CHOL and FFA in gastrocnemius C) Triglyceride quantity decreased in Mstn KO muscle compared with WT ( $\mathrm{n}=7$ per group). Values are shown as means \pm SEM. FAS, fatty acid synthase; Tub: $\alpha$-tubulin; FFA: free fatty acids; CHOL: cholesterol, TG: triglycerides. P-Values were calculated using the parametric test T-student $\left(* \mathrm{p}<0.05 .{ }^{* *} \mathrm{p}<0.01\right)$ AU: Arbitrary Units. 


\section{Modification of fatty acid composition in Mstn KO muscle}

The structural unit of lipids is the FA, which is divided in three groups: saturated fatty acids (SFAs), monounsaturated fatty acids (MUFAs) and polyunsaturated fatty acids (PUFAs). Table 3 shows distribution of 11 FAs of gastrocnemius muscle in WT and KO mice. The ratio 22:6n-3/20:4n-6 is 2 to 3, both in WT and KO mouse muscle, as previously reported in skeletal muscle tissue [49,50]. Mstn KO mice contained higher percent of SFAs $(46.2 \pm 3.7 \%$ vs $40.3 \pm 2.8 \%, p<0.01)$, as well as PUFAs $(38.6 \pm 1.5 \%$ vs $36.3 \% \pm 1.4 \%, p<0.01)$ with increased proportion of $20: 3 n-6,20: 4 n-6,20: 5 n-3$ and 22:5n-3. Interestingly, among PUFAs, an exception with the 18:2n-6, linoleic acid is noticed with a trend of reduced expression in mstn KO gastrocnemius muscle compared to controls ( $\mathrm{p}=0.092)$. Mstn KO mice contained lower percent of MUFA $(15.2 \pm 3.4 \%$ vs $23.4 \pm 3.7 \%, p<0.001)$ than WT. We further focused our attention on the fatty acid desaturases ( $\Delta$-9-desaturase and $\Delta$-5-desaturase) that are involved in the synthesis of unsaturated fatty acids. Interestingly, we found a strong decrease of the index of desaturase 9 activity (16:1n-7/16:0 and 18:1n-9/18:0) (Table 3), which was paralleled by a strong decrease in $\Delta$-9-desaturase protein levels (also known as stearoyl-CoA desaturase SCD) in Mstn KO muscle (Figure 5).
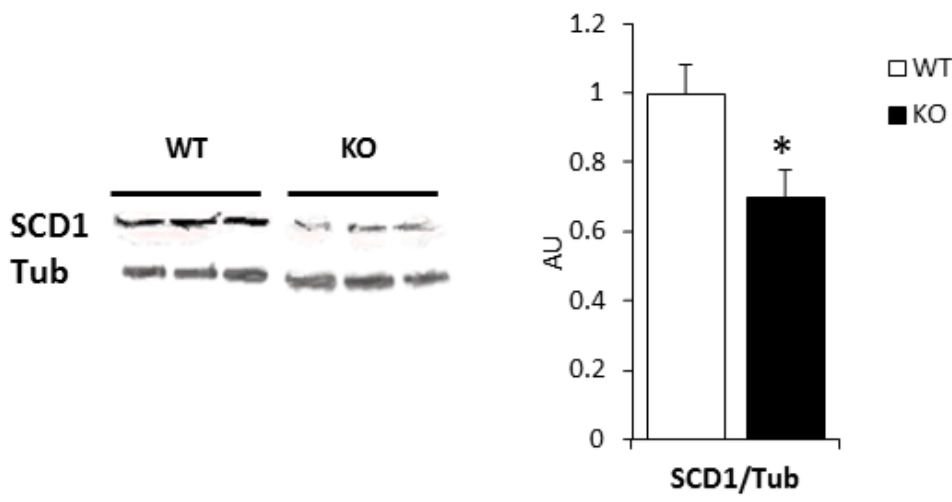

Figure 5 Stearoyl-CoA desaturase is reduced in gastrocnemius muscles of Mstn KO mice Quantification of SCD1 protein levels expressed relative to $\alpha$-tubulin levels in gastrocnemius muscles of WT and KO mice revealed by Western blot. Each lane depicts signal obtained from $50 \mu \mathrm{g}$ of muscle protein from one animal after western-blot analysis. Values are means \pm SEM. P-Values were calculated using the parametric test T-student $(* \mathrm{p}<0.05) ; \mathrm{n}=8$ per group. 


\begin{tabular}{|c|c|c|c|c|}
\hline & Fatty acid & $\begin{array}{c}\text { WT } \\
(n=8)\end{array}$ & $\begin{array}{c}\text { КО } \\
(n=7)\end{array}$ & p values \\
\hline Total SFA & & $40.3 \pm 2.8$ & $46.2 \pm 3.7^{* *}$ & 0.0043 \\
\hline $16: 0$ & Palmitic acid & $26.8 \pm 1.3$ & $29.5 \pm 1.7^{* *}$ & 0.0056 \\
\hline $18: 0$ & Stearic acid & $10.8 \pm 1.5$ & $13.9 \pm 1.4^{* *}$ & 0.0016 \\
\hline Total MUFA & & $23.4 \pm 3.7$ & $15.2 \pm 3.4^{* * *}$ & 0.0008 \\
\hline $16: 1 n-7$ & Palmitoleic acid & $5.4 \pm 1.2$ & $2.4 \pm 0.9^{* * *}$ & 0.0001 \\
\hline $18: 1 n-9$ & Oleic acid & $14.0 \pm 2.6$ & $8.8 \pm 2.6^{* *}$ & 0.0022 \\
\hline $18: 1 n-7$ & Vaccenic acid & $2.4 \pm 0.1$ & $2.4 \pm 0.1$ & 0.61 \\
\hline Total PUFA & & $36.3 \pm 1.4$ & $38.6 \pm 1.5^{* *}$ & 0.0078 \\
\hline $18: 2 n-6$ & Linoleic acid & $16.5 \pm 1.4$ & $14.7 \pm 2.3$ & 0.092 \\
\hline $20: 3 n-6$ & Dihomo- $\gamma$-linolenic acid & $0.5 \pm 0.7$ & $0.7 \pm 0.1^{* * *}$ & 0.0001 \\
\hline $20: 4 n-6$ & Arachidonic acid & $4.5 \pm 0.6$ & $6.6 \pm 0.5^{* * *}$ & $<0.0001$ \\
\hline $20: 5 n-3$ & acid & $0.1 \pm 0.0$ & $0.3 \pm 0.1^{* *}$ & 0.0058 \\
\hline $22: 5 n-3$ & Clupanodonic acid & $1.4 \pm 0.2$ & $2.1 \pm 0.3^{* * *}$ & 0.0002 \\
\hline $22: 6 n-3$ & Docosahexaenoic acid & $11.1 \pm 1.7$ & $11.8 \pm 1.6$ & 0.4 \\
\hline Total $(n-6)$ & & $22.6 \pm 0.7$ & $23.5 \pm 1.8$ & 0.23 \\
\hline Total (n-3) & & $13.7 \pm 1.8$ & $15.1 \pm 1.8$ & 0.17 \\
\hline$(n-6) /(n-3)$ & & $1.7 \pm 0.2$ & $1.6 \pm 0.2$ & 0.53 \\
\hline \multicolumn{5}{|l|}{$\Delta$-9-désaturase } \\
\hline $18: \ln -9 / 18: 0$ & & $1.3 \pm 0.4$ & $0.6 \pm 0.2^{* *}$ & 0.005 \\
\hline c16:1n-7/16:0 & & $0.2 \pm 0.1$ & $0.1 \pm 0.0^{* * *}$ & 0.0002 \\
\hline$\Delta$-5-desaturase & & $9.4 \pm 0.7$ & $9.5 \pm 0.6$ & 0.66 \\
\hline ¿Dimethylacetals & & $0.6 \pm 0.1$ & $0.8 \pm 0.1$ & 0.07 \\
\hline
\end{tabular}

Table 3: Lipid fatty acids composition in gastrocnemius muscle (mg FA/g muscle) Fatty acids distribution in WT $(n=8)$ and Mstn KO (n=7) muscle evaluated by gas chromatography. SFAs, saturated fatty acids; MUFAs, monounsaturated fatty acids; PUFAs, polyunsaturated fatty acids. Relative plasmalogens amount were evaluated by quantification of the relative dimethylacetals 16 and 18 amount (DMA16:0 and DMA18:0). Values are shown as means \pm SEM. P-Values were calculated using the parametric test T-student or Mann-Whitney test when the normality was not obtained $(* * \mathrm{p}<0.01 ; * * * \mathrm{p}<0.001)$. 


\section{Modification in phospholipids composition in Mstn KO muscle}

Then, we identified and compared the lipid patterns of gastrocnemius muscle from wild type and Mstn KO mice between the different phospholipids quantity by thin layer chromatography. Among different phospholipids analyzed, we observed a significant decrease in CL levels in Mstn KO suggesting modifications in mitochondria membrane phospholipid composition (Figure 6).

A)
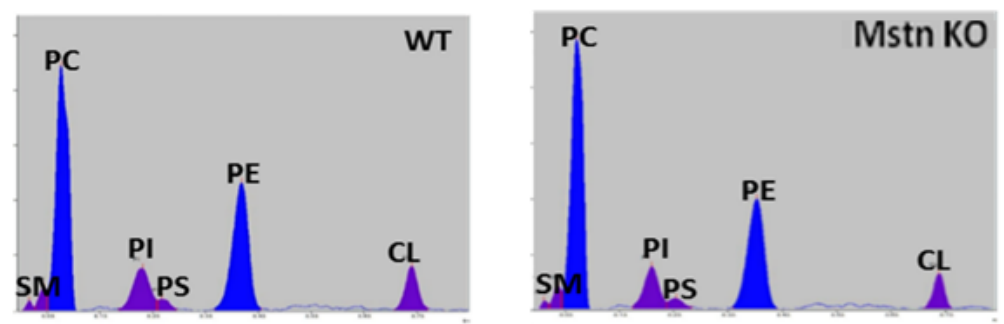

B)

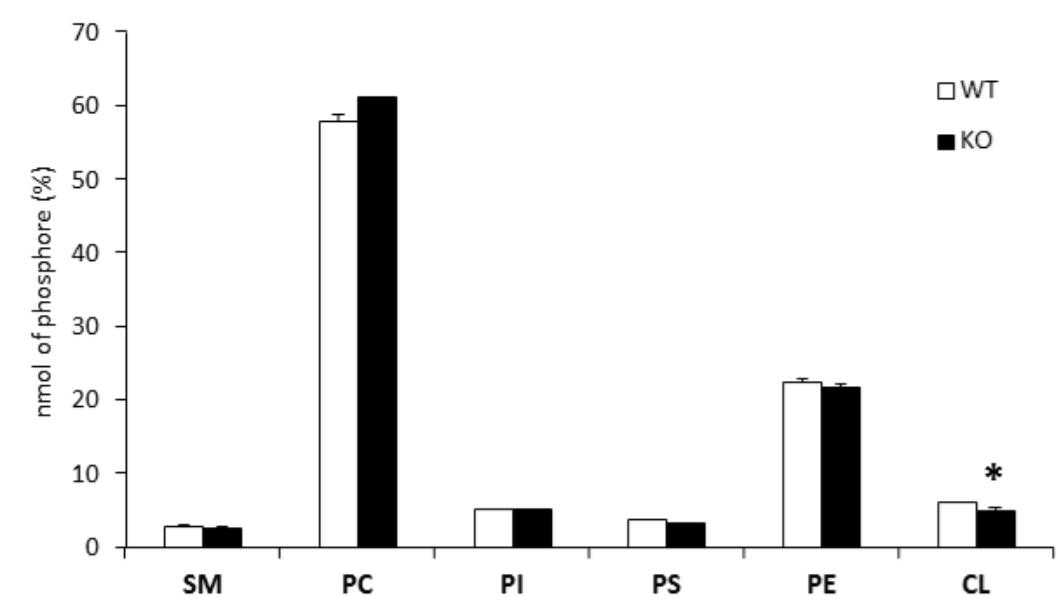

Figure 6: Phospholipid composition of gastrocnemius muscle in WT and Mstn KO mice.

A) Representative thin-layer chromatographic profile of the extracted lipids. Sphingomyelin (SM), Phosphatidylcholine (PC), Phosphatidylinositol (PI), Phosphatidylserine (PS), Phosphatidyletanolamine (PE) and Cardiolipin (CL) were detected with phospholipid separation. B) Quantification of phospholipids in gastrocnemius muscle of WT and Mstn KO mice. Results are expressed as percentage of nmol of phosphorus in total phospholipids. Values are shown as means \pm SEM, p-values were calculated using the parametric test Tstudent, except for $\mathrm{CL} ; * \mathrm{p}<0.05$ vs WT); $\mathrm{n}=8$ per group).

\section{Impaired phospholipid mitochondrial membrane composition in Mstn KO muscle.}

As Mstn deficiency led to a congenital shift towards fast glycolytic muscle fibers and a reduction in mitochondrial content, afterwards we identified and compared the lipid patterns of mitochondria membranes from wild type and Mstn KO mice using the same technique using mixed muscle samples. Figure 7A shows the thin-layer chromatographic profile of the extracted lipids. The amount of SM, PI and PS was higher in Mstn KO mitochondria compared with WT (Figure 7B) whereas no change in major membrane phospholipids PC and PE was observed in the two groups of mice. 

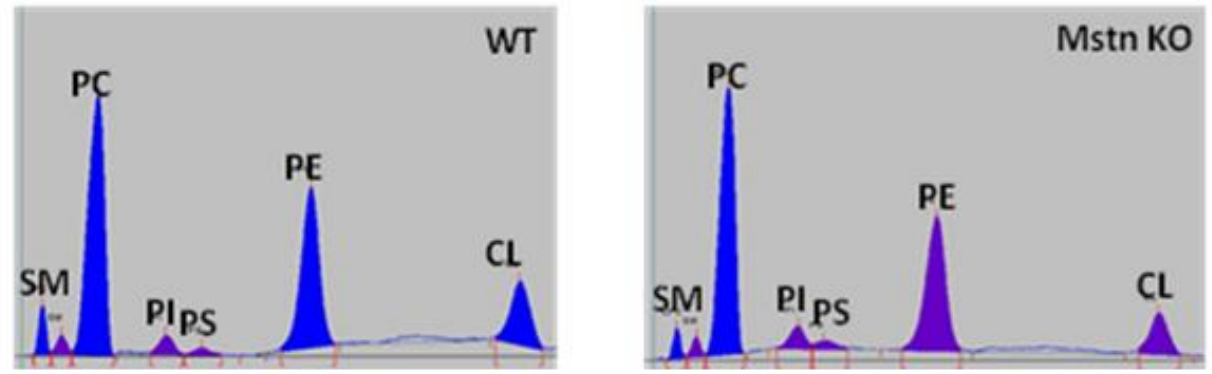

B)

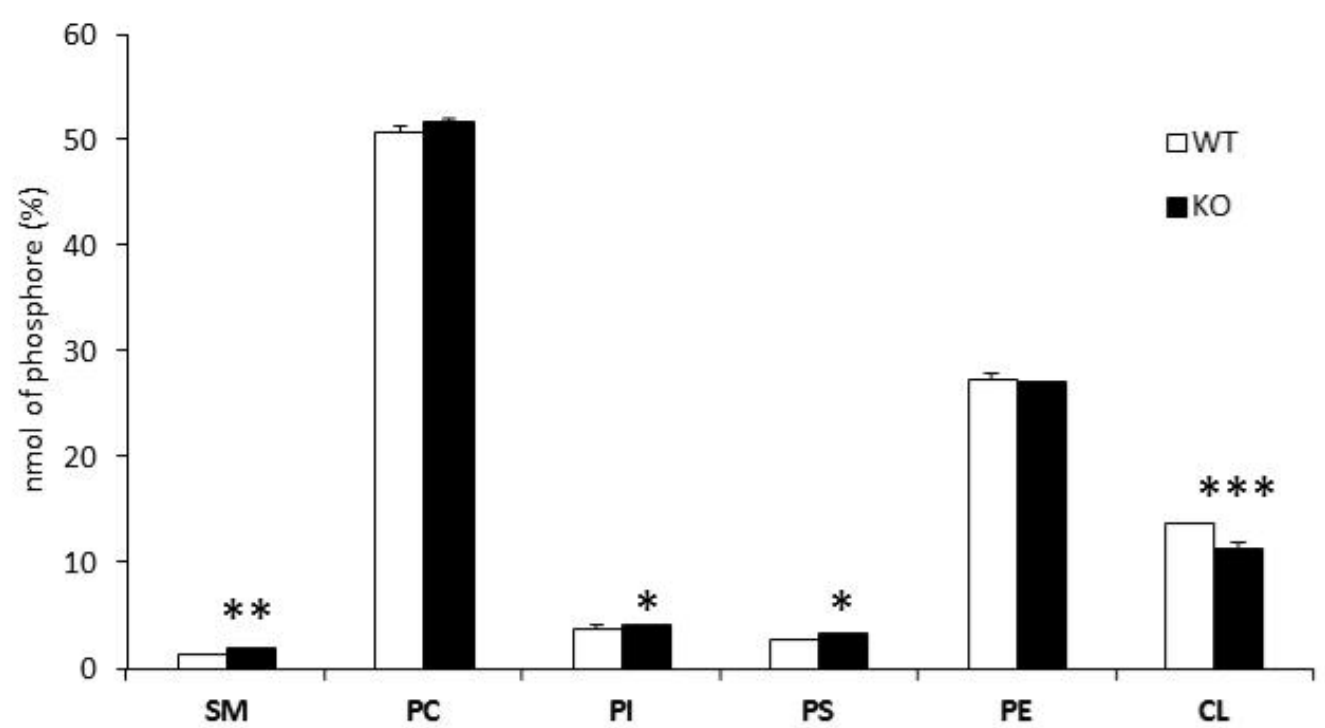

Figure 7: Phospholipids composition of mitochondrial membrane in mixed limb muscles in WT and Mstn KO mice. A) Representative thin-layer chromatographic profiles of the extracted lipids. Sphingomyelin (SM), Phosphatidylcholine (PC), Phosphatidylinositol (PI), Phosphatidylserine (PS), Phosphatidyletanolamine (PE) and cardiolipin (CL) were detected with phospholipid separation. B) Quantification of phospholipids in mitochondrial membranes of mixed limb muscles of WT and Mstn KO mice. Results are expressed as percentage of nmol of phosphorus in total phospholipids. Values are shown as means \pm SEM, p-values were calculated using the parametric test T-student $(* \mathrm{p}<0.05 ; * * \mathrm{p}<0.01$, *** $\mathrm{p}<0.001$ vs WT). (n=8 per group).

Interestingly, there was a reduction in CL proportion (mean 12\%) in mitochondria membrane versus the proportion of others phospholipids in mstn KO mice compared to WT (Figure 7B), revealing a qualitative impact of mstn deficiency on mitochondrial membrane composition. We estimated the mitochondria CL content expressing in $\mu \mathrm{moL}$ of phosphorus in CL per mg of mitochondrial protein, and confirmed the reduced content (reduction of 23\%) in mstn KO muscle compared with WT $(0.07 \mu \mathrm{moL} v s 0.09 \mu \mathrm{moL}$ of Phosphorus in $\mathrm{CL} / \mathrm{mg}$ mitochondria protein, respectively, $\mathrm{p}<0.05)$ suggesting a quantitative impact of mstn deficiency on CL. To determine if these impacts on CL metabolism were specific to skeletal muscles, complementary control analysis on heart mitochondria was made. Contrary to skeletal muscle, results revealed similar cardiolipin proportion and content in heart mitochondria membranes in mstn KO mice compared to WT (12.8 $\pm 1.3 v s 12.4 \pm 1.1$ respectively, expressed as percentage of nmol of phosphorus in total phospholipids and $0.13 \pm 0.02$ vs $0.09 \pm 0.01$ respectively, expressed in $\mu \mathrm{moL}$ of phosphorus in CL per $\mathrm{mg}$ of mitochondrial protein). 


\section{Cardiolipin synthesis pathway in Mstn KO muscle mitochondria}

Thereafter, we examined the enzymes involved in CL synthesis (CLS: Cardiolipin synthase, Pgps: phosphatidylglycerolphosphate synthase) and CL remodeling (Alcat1: ER-associated monolyso-CL acyltransferase, Taz: tafazzin). At the protein level, the amount of CLS is lower in the mstn deficient muscle normalized by $\alpha$-tubulin or by CS abundance (Figure 8A). Furthermore mRNA level of Pgps was also significantly decreased in Mstn KO muscle (Figure 8B) whereas the expression of the genes involved in the remodeling of CL acyl chains (Alcat1, Taz) did not change.

A)

B)
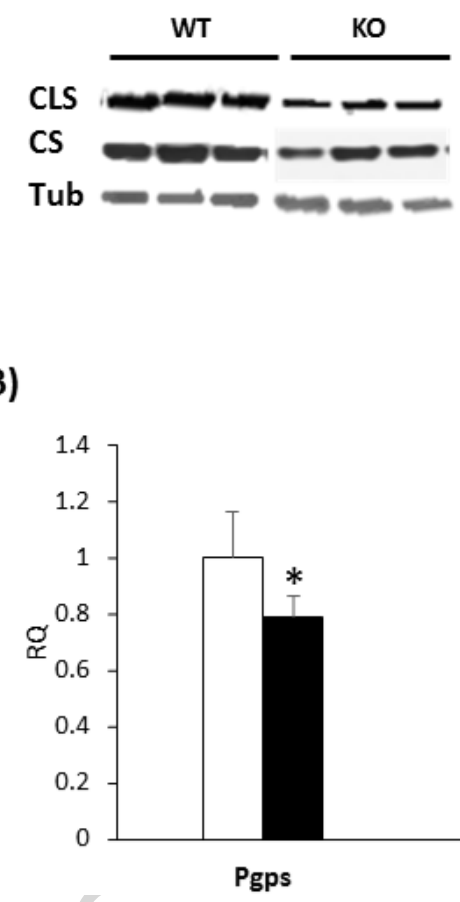
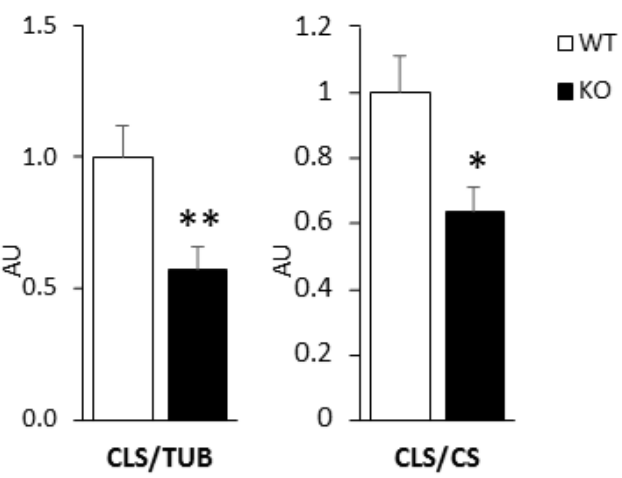

Figure 8: Expression of enzymes of cardiolipin synthetic route. A) Endogenous CLS, CS and $\alpha$-tubulin (as a loading control) were detected by western blot analysis using specific antibodies. CLS quantity was evaluated by Western Blot in KO gastrocnemius muscle and WT standardised either with $\alpha$-tubulin or CS in mitochondria.

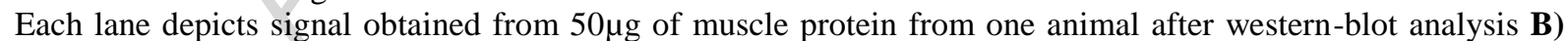
Gene expression of Pgps, Taz and Alcat1 enzymes evaluated by RT-PCR in KO and WT muscle. Values are shown as means \pm SEM. p-values were calculated using the parametric test T-student $\left({ }^{*} p<0.05 ; * * p<0.01\right)$. AU: Arbitrary Units, RQ: Relative Quantity. CLS: cardiolipin synthase, CS: citrate synthase, Pgps: phosphatidylglycerolphosphate synthase, Taz: taffazin, Alcat1: ER-associated monolyso-CL acyltransferase ( $\mathrm{n}=8$ per group). 


\section{Discussion}

MSTN is a potent inhibitor of skeletal muscle mass. Mice lacking MSTN exhibit a strong hypermuscular phenotype and a faster and more glycolytic muscle phenotype. Previous work in our laboratory revealed in Mstn $\mathrm{KO}$ mice significant functional abnormalities of inter-myofibrillar mitochondria, that are primarily involved in the process of muscle contraction [13]. These abnormalities are characterized by a decrease in the efficiency of mitochondrial respiratory coupling, resulting in excess oxygen consumption for the same production of ATP. Such mitochondrial oxidative and metabolic alterations have also been reported in mice with partial inhibition of MSTN using anti-MSTN antibody [15,51,52]. However it is still unknown how Mstn inhibition would influence the mitochondrial function. We explored the hypothesis that MSTN can impact the regulation of lipid synthesis and mitochondrial lipid content, thus affecting mitochondrial function.

In this study, we demonstrated for the first time Mstn KO mice showed alterations in lipid composition of mitochondrial membranes. In fact, we demonstrated in Mstn KO muscle a full decline in lipid pathways such as fatty acid uptake, fatty acid oxidation and fatty acid synthesis (lipogenesis) coupled to a shift in fatty acids composition illustrated by an increase in SFA and PUFA levels at the expense of MUFA levels. Interestingly, we observed a significant decrease in the proportion of CL in Mstn KO mitochondrial membranes. These findings provide evidence that at least part of the mechanism by which MSTN regulates mitochondria function is by modulating the lipid metabolism and mitochondrial membrane phospholipid composition.

\section{Myostatin and muscle lipid metabolism}

Here, we showed that Mstn gene deletion results in reduced lipolytic machinery in Mstn deficient hypertrophic muscles (impaired mitochondrial yield, CS and $\beta-\mathrm{HAD}$ activities and Cpt1 and Ppar- $\delta$ gene expressions), in line with previous studies showing that oxidative metabolism is diminished in several models of Mstn deficiency [12,13, 15,16,51]. In addition, we demonstrated that the levels of cytosolic (FABP3) and sarcolemmal lipid transporters (FATP1, FATP4) are reduced, in agreement with our previous observation showing a significant reduction of FAT/CD36 levels [16]. It should be noted that CD36, FABP3, FATP1 and FATP4 are co-expressed in skeletal muscle, and all of these proteins contributed to transport, with recent evidence suggesting that CD36 and FATP4 are qualitatively the most important [53]. Our results indicated that the process regulating fatty acids uptake into muscle by protein-mediated transport is negatively and strongly affected by MSTN deficiency. Interestingly, by evaluating lipogenesis in Mstn KO muscle, we found a marked decrease in triglycerides levels (70\%) compared to WT muscles, correlating with the decline of FAS activity recorded. Collectively, our data pointed a role for MSTN in the regulation of muscle lipid metabolism, with a lower capacity to store, mobilize and oxidize lipids. This deficit in lipid pathway observed in our present study is counterbalanced by the increased glucose oxidation previously shown in MSTN deficient muscle by the group of McPherron. Indeed, Mstn KO mice have increased glucose utilization 
and insulin sensitivity thanks to an increase in glucose uptake in muscle and adipose tissues [54]. In the same vein, Relizani et al. reported that the blockade of mstn decreased mRNA levels of Pdk4, a regulatory protein switch of substrate utilization from glucose towards fatty acids [15]. In a previous study, we observed in aged Mstn KO EDL muscle a significant increase in GLUT4 protein levels, and a decrease in FAT/CD36 protein levels compared to aged WT mice [16]. In the present study, we confirm the increased content of muscle glucose uptake markers in mstn KO muscle. Given that FA and glucose are the main energy sources in skeletal muscle, these results suggest that MSTN could contribute to the fine regulation for the use of these two substrates. Our results demonstrate that mstn deficient muscle malfunctions for fat handling that could explain metabolic shift towards glycolytic pathway.

\section{Myostatin and membrane phospholipids composition}

Phospholipids affect function of protein machineries involved in respiratory metabolism, protein import, membrane architecture and mitochondrial dynamics [24]. At this point, we hypothesized that muscle lipid metabolism alterations related to MSTN deficiency can impact muscle lipid composition. We observed changes in FA composition, and components of phospholipids, in deficient Mstn muscles, concomitant with an increase in SFAs at the expense of MUFAs. This was accompanied by a down-regulation of SCD1. Of note, the promoter of Scd1 gene contains a Ppar response element sequence [55]; therefore the down-regulation of Ppar $\delta$ that we have seen in absence of mstn could result in decreased gene transcription of Scd1. As Scd1 converts SFA to MUFA, the down-regulation of this enzyme supports a shift away MUFA towards SFA. Biosynthesis PUFAs of the $n-6$ and $n-3$ series occurs via sequential desaturation, elongation and partial degradation step [56]. In our work, the impact of mstn deficiency on increased $\Delta-5$ and $\Delta-6$ desaturase activity is unlikely, as we noticed no significant change in $\Delta-5$ desaturase activity between mice groups. Moreover, 22:6n-3 proportion (docosahexaenoic acid), reflecting indirectly $\Delta-6$ desaturase activity, was no modified. The hypothesis of increased elongase and/or $\Delta-8$ desaturase activities in mstn $\mathrm{KO}$ muscle cannot be excluded. Finally, as mstn KO muscle exhibited higher significant proportion of 22:5n-3, but not of 22:6n-3, the hypothesis of an inhibited peroxysomal $\beta$-oxidation can be also advanced [56].

The lipid tails of the phospholipids composing the plasma membranes can affect mechanical properties. Membrane fluidity is promoted by lipids with short, unsaturated fatty acids [57]. In DMD differentiated muscle cells, Le Borgne et al., identified an increase in PUFA and a decrease in MUFA as well as cholesterol contents. That changes affected mechanical properties, as reduced membrane fluidity was observed by fluorescence anisotropy [58]. In line with our results and these previous studies, we hypothesize a trend towards stiff and rigid membranes in Mstn KO skeletal muscles. The functional and clinical relevance of these modifications on muscle membrane fluidity has yet to be investigated in mstn KO model. 
We next focused on mitochondrial membranes, where localized proteins and complexes of the respiratory chain work together to produce ATP. In mstn KO mitochondrial membranes, we found abnormalities in the proportion of specific lipids, including a decrease (about 12\%) in the proportion of CL while SM, PI and PS are slightly but significantly increased. This result revealed a qualitative impact of mstn deficiency on mitochondria membrane composition, with reduced proportion of mitochondrial CL levels, an important regulator of mitochondrial metabolism. Furthermore, mitochondrial CL content reduced of $23 \%$ in mstn $\mathrm{KO}$ mice suggesting also quantitative impact of mstn deficiency on CL metabolism. This reduction approximates values published in previous studies related to cardiolipin and diseases, in particular those from group of Paradies et al indicating that low levels of cardiolipin in heart mitochondria (approximating 30-40\% reduction) from aged or hypothyroid rats were accompanied by lower activities of the pyruvate carrier and cytochrome oxidase and dysfunction [59-63]. Our results suggest both qualitative (reduction of 12\% in the proportion) and quantitative (reduction of $23 \%$ in quantity) impacts of mstn deficiency on mitochondrial cardiolipin pathway.

If it is difficult to distinguish between a causal role of cardiolipin and a correlative effect, in one study, replenishment with cardiolipin of hypothyroid mitochondria restored the activity of cytochrome oxidase to control levels [60]. Synthesized in the inner mitochondrial membrane, nascent CL undergoes a remodelling process to form the mature CL [24]. Our results on enzymes involved in CL formation indicated that MSTN deficiency likely negatively affected synthesis, rather than remodeling process, that induced the lower abundance of CL. It should be added that we showed in mstn KO gastrocnemius a tendency towards the reduction of linoleic acid (18:2n-6), the most abundant fatty acid in CL [64]. As a close interplay between CL biosynthesis and oxidative phosphorylation is recognized [24], our results raise the question of the link with the compromised bioenergetic capacity observed in this hypertrophic muscle. We recognize that direct evidence is still missing, and should be discussed with caution. However, our results suggest a specific effect on skeletal muscle. Indeed, no impact of mstn deficiency has been observed on mitochondrial CL proportion /content in heart, an organ without functional impairment in this mice model. These results strengthen and highlight correlation between cardiolipin pathway and mitochondrial impairment, as only skeletal muscle from mstn KO mice presents both qualitative and quantitative impacts on mitochondrial membrane cardiolipin pathway with oxidative mitochondrial and functional disorders. CL plays an essential role in maintaining an adequate membrane potential [65], but arguably, the most important function of CL in mitochondria is the effect it has on the association of protein complexes and supercomplexes [25]. Actually, this specific phospholipid of the mitochondria plays an important role in respiratory chain (biogenesis, stability and activity of the respiratory complexes), in the $\beta$ oxidation of fatty acids and is involved in the last step of energy conversion, namely the production of ATP [24-26]. Crystallographic and nuclear magnetic resonance studies showed the presence of CL, in 
particular the species rich in 18:2n-6, associated with complex I, III and IV, with the ATPsynthase and the ANT $[66,25]$ and its presence is essential for the functionality structure of these proteins, and thus for their optimal activity ([25] For Review). For instance, the full transport activity of the ADP/ATP carrier depends on the presence of CL [67]. Inversely, the oligomerization state of ADP/ATP carrier in mitochondria, and its association with other protein complexes are altered in the absence of CL [68]. Interestingly, our previous data highlighted metabolic perturbations exclusively in the respiration of intermyofibrillar (IMF) mitochondria from Mstn-deficient muscle [13]. In diabetes mellitus type 1, cardiolipin content is decreased in the IMF subpopulation, but not in the in the sub-sarcolemmal subpopulation [69,70]. The decrease in CL mitochondria content, demonstrated in our study, could thus lead to the uncoupling in the mitochondria respiration (decay in the respiratory ratio control in the IMF mitochondria) and the decrease in ATP production previously reported in mstn KO muscle $[13,71]$. Consequently, we propose that the significant decrease in CL in Mstn $\mathrm{KO}$ mice, pointing to a defect of IMF, as one causative mechanism for the metabolic phenotype.

Our results reveal alterations in mitochondrial membrane lipids related to MSTN deficiency. How can we link membrane lipid changes to MSTN? We showed that MSTN deficiency downregulates expression of PPAR $\delta$ transcription factor, which regulates fatty acid transport and oxidation in skeletal muscle [72-75]. Indeed, genes involved in energy metabolism including Fatp, Pdk4 are induced by a PPAR $\delta$ specific agonist. In addition, Wang et al. showed that the PPAR $\delta$-mediated reprogramming of muscle fiber involves the increased expression of genes related to fatty acid oxidation, mitochondrial respiration, oxidative metabolism, and slow-twitch contractile apparatus [73]. This suggests that MSTN might regulate membrane lipid changes via PPAR activity. Since Mstn KO mice have fiber hypertrophy in muscles composed predominantly of fast glycolytic fibers [12,[76], it is possible that the decrease in oxidative metabolism and $\beta$-oxidation is an indirect effect and related to the fast-twitch phenotype. In fact, PPAR $\delta$ is preferentially found in oxidative rather than glycolytic myofibers [73]. Nevertheless, reduction of oxidative metabolism has been demonstrated using postnatal Mstn inhibition, where fiber type composition was not affected [15,69,77]. Furthermore, no difference has been noted in the percentage of CL in mitochondria from muscles with varying oxidative potentials, as well as in the percent of phospholipid head groups or major fatty acid subclasses [70]. However, rates of palmitate oxidation were positively correlated with both the unsaturation index and relative abundance of cardiolipin within mitochondria [69]. Overall, this suggests that the glycolytic shift cannot be the only mechanism to explain oxidative metabolism decline and membrane lipid changes in Mstn KO mice. 


\section{Conclusion and perspectives}

To conclude, the results of the present study show that MSTN absence significantly alters the mitochondrial lipidome. This abnormality may be related to the impairment in mitochondrial function and the higher susceptibility to fatigue in this hypertrophic model, as lipids and in particular cardiolipin play central roles in optimal mitochondrial function. Future studies that modulate the membrane phosphoslipid composition in mitochondria and muscle in Mstn deficient models will be required for rigorous examination of how the abundance of each class of phospoholipids becomes optimized, and in turn affects mitochondrial respiratory function and oxidative metabolism. In this context, nutritional regimes or endurance training are two potential strategies to induce a remodelling of mitochondrial membrane phospholipid composition [78,79], and thus should be studied in the future to elucidate the link between membrane lipid changes and mstn signalling pathway.

\section{Funding}

This study was supported by funds from the Institut National de la Recherche Agronomique (INRA) and the University of Montpellier. N.B. is the recipient of doctoral fellowship financed by the Tunisian National Ministry of Higher Education and Research.

\section{Ethical statements}

The manuscript does not contain clinical studies or patient data. The experimental protocols of this study were handled in strict accordance with European directives on animal right (86/609/CEE) and approved by the Ethical Committee of Region Languedoc Roussillon (APAFIS\#25512015110311365663v2).

Furthermore, the authors declare that they have no conflict of interest.

\section{Acknowledgments}

We also would like to thank the animal staff from our METAMUS platform facility, which belongs to "Montpellier animal facilities network" (RAM): Sylvain Cerda, Romain Godoye, Mélanie Macart, and Christelle Bertrand-Gaday, as well as Bruno Baréa (CIRAD, UMR IATE,F-34398) for his technical assistance on GC analysis. Special thanks go to Ayesha Saleem, Vincent Ollendorff, and Amel Zroud for critical readings of the manuscript. 


\section{References}

[1] A.C. McPherron, A.M. Lawler, S.J. Lee, Regulation of skeletal muscle mass in mice by a new TGF-beta superfamily member, Nature. 387 (1997) 83-90.

[2] L. Grobet, L.J. Martin, D. Poncelet, D. Pirottin, B. Brouwers, J. Riquet, A. Schoeberlein, S. Dunner, F. Ménissier, J. Massabanda, R. Fries, R. Hanset, M. Georges, A deletion in the bovine myostatin gene causes the double-muscled phenotype in cattle, Nat. Genet. 17 (1997) 71-74.

[3] R. Kambadur, M. Sharma, T.P. Smith, J.J. Bass, Mutations in myostatin (GDF8) in doublemuscled Belgian Blue and Piedmontese cattle, Genome Res. 7 (1997) 910-916.

[4] A. Clop, F. Marcq, H. Takeda, D. Pirottin, X. Tordoir, B. Bibé, J. Bouix, F. Caiment, J.-M. Elsen, F. Eychenne, C. Larzul, E. Laville, F. Meish, D. Milenkovic, J. Tobin, C. Charlier, M. Georges, A mutation creating a potential illegitimate microRNA target site in the myostatin gene affects muscularity in sheep, Nat. Genet. 38 (2006) 813-818.

[5] M. Schuelke, K.R. Wagner, L.E. Stolz, C. Hübner, T. Riebel, W. Kömen, T. Braun, J.F. Tobin, S.J. Lee, Myostatin mutation associated with gross muscle hypertrophy in a child, N. Engl. J. Med. 350 (2004) 2682-2688.

[6] S. Bogdanovich, T.O.B. Krag, E.R. Barton, L.D. Morris, L.-A. Whittemore, R.S. Ahima, T.S. Khurana, Functional improvement of dystrophic muscle by myostatin blockade, Nature. 420 (2002) 418-421.

[7] Y. Ohsawa, T. Okada, S.-I. Nishimatsu, M. Ishizaki, T. Suga, M. Fujino, T. Murakami, M. Uchino, K. Tsuchida, S. Noji, A. Hinohara, T. Shimizu, K. Shimizu, Y. Sunada, An inhibitor of transforming growth factor beta type I receptor ameliorates muscle atrophy in a mouse model of caveolin 3-deficient muscular dystrophy, Lab. Investig. J. Tech. Methods Pathol. 92 (2012) 11001114.

[8] L. Zhang, V. Rajan, E. Lin, Z. Hu, H.Q. Han, X. Zhou, Y. Song, H. Min, X. Wang, J. Du, W.E. Mitch, Pharmacological inhibition of myostatin suppresses systemic inflammation and muscle atrophy in mice with chronic kidney disease, FASEB J. Off. Publ. Fed. Am. Soc. Exp. Biol. 25 (2011) 1653-1663.

[9] E.L.F. Holzbaur, D.S. Howland, N. Weber, K. Wallace, Y. She, S. Kwak, L.A. Tchistiakova, E. Murphy, J. Hinson, R. Karim, X.Y. Tan, P. Kelley, K.C. McGill, G. Williams, C. Hobbs, P. Doherty, M.M. Zaleska, M.N. Pangalos, F.S. Walsh, Myostatin inhibition slows muscle atrophy in rodent models of amyotrophic lateral sclerosis, Neurobiol. Dis. 23 (2006) 697-707.

[10]K.R. Wagner, Muscle regeneration through myostatin inhibition, Curr. Opin. Rheumatol. 17 (2005) 720-724. 
[11]H. Amthor, R. Macharia, R. Navarrete, M. Schuelke, S.C. Brown, A. Otto, T. Voit, F. Muntoni, G. Vrbóva, T. Partridge, P. Zammit, L. Bunger, K. Patel, Lack of myostatin results in excessive muscle growth but impaired force generation, Proc. Natl. Acad. Sci. U. S. A. 104 (2007) 18351840.

[12]C.L. Mendias, J.E. Marcin, D.R. Calerdon, J.A. Faulkner, Contractile properties of EDL and soleus muscles of myostatin-deficient mice, J. Appl. Physiol. Bethesda Md 1985. 101 (2006) 898905.

[13]C. Ploquin, B. Chabi, G. Fouret, B. Vernus, C. Feillet-Coudray, C. Coudray, A. Bonnieu, C. Ramonatxo, Lack of myostatin alters intermyofibrillar mitochondria activity, unbalances redox status, and impairs tolerance to chronic repetitive contractions in muscle, Am. J. Physiol. Endocrinol. Metab. 302 (2012) E1000-1008.

[14]B. Giannesini, C. Vilmen, H. Amthor, M. Bernard, D. Bendahan, Lack of myostatin impairs mechanical performance and ATP cost of contraction in exercising mouse gastrocnemius muscle in vivo, Am. J. Physiol. Endocrinol. Metab. 305 (2013) E33-40.

[15]K. Relizani, E. Mouisel, B. Giannesini, C. Hourdé, K. Patel, S. Morales Gonzalez, K. Jülich, A. Vignaud, F. Piétri-Rouxel, D. Fortin, L. Garcia, S. Blot, O. Ritvos, D. Bendahan, A. Ferry, R. Ventura-Clapier, M. Schuelke, H. Amthor, Blockade of ActRIIB signaling triggers muscle fatigability and metabolic myopathy, Mol. Ther. J. Am. Soc. Gene Ther. 22 (2014) 1423-1433.

[16]M. Pauly, B. Chabi, F.B. Favier, F. Vanterpool, S. Matecki, G. Fouret, B. Bonafos, B. Vernus, C. Feillet-Coudray, C. Coudray, A. Bonnieu, C. Ramonatxo, Combined Strategies for Maintaining Skeletal Muscle Mass and Function in Aging: Myostatin Inactivation and AICAR-Associated Oxidative Metabolism Induction, J. Gerontol. A. Biol. Sci. Med. Sci. 70 (2015) 1077-1087.

[17]E. Ojuka, B. Andrew, N. Bezuidenhout, S. George, G. Maarman, H.P. Madlala, A. Mendham, P.O. Osiki, Measurement of $\beta$-oxidation capacity of biological samples by respirometry: a review of principles and substrates, Am. J. Physiol. Endocrinol. Metab. 310 (2016) E715-723.

[18]C. Saponaro, M. Gaggini, F. Carli, A. Gastaldelli, The Subtle Balance between Lipolysis and Lipogenesis: A Critical Point in Metabolic Homeostasis, Nutrients. 7 (2015) 9453-9474.

[19]E.M. Mejia, G.M. Hatch, Mitochondrial phospholipids: role in mitochondrial function, J. Bioenerg. Biomembr. 48 (2016) 99-112.

[20]T.D. Heden, P.D. Neufer, K. Funai, Looking Beyond Structure: Membrane Phospholipids of Skeletal Muscle Mitochondria, Trends Endocrinol. Metab. TEM. 27 (2016) 553-562.

[21]R.B. Sher, C. Aoyama, K.A. Huebsch, S. Ji, J. Kerner, Y. Yang, W.N. Frankel, C.L. Hoppel, P.A. Wood, D.E. Vance, G.A. Cox, A rostrocaudal muscular dystrophy caused by a defect in choline kinase beta, the first enzyme in phosphatidylcholine biosynthesis, J. Biol. Chem. 281 (2006) 4938-4948. 
[22]G. Wu, R.B. Sher, G.A. Cox, D.E. Vance, Understanding the muscular dystrophy caused by deletion of choline kinase beta in mice, Biochim. Biophys. Acta. 1791 (2009) 347-356.

[23]S. Mitsuhashi, H. Hatakeyama, M. Karahashi, T. Koumura, I. Nonaka, Y.K. Hayashi, S. Noguchi, R.B. Sher, Y. Nakagawa, G. Manfredi, Y. Goto, G.A. Cox, I. Nishino, Muscle choline kinase beta defect causes mitochondrial dysfunction and increased mitophagy, Hum. Mol. Genet. 20 (2011) $3841-3851$.

[24]C.U. Mårtensson, K.N. Doan, T. Becker, Effects of lipids on mitochondrial functions, Biochim. Biophys. Acta. 1862 (2017) 102-113.

[25]M. Schlame, M.L. Greenberg, Biosynthesis, remodeling and turnover of mitochondrial cardiolipin, Biochim. Biophys. Acta. 1862 (2017) 3-7.

[26]G. Paradies, V. Paradies, V. De Benedictis, F.M. Ruggiero, G. Petrosillo, Functional role of cardiolipin in mitochondrial bioenergetics, Biochim. Biophys. Acta. 1837 (2014) 408-417.

[27]M.J. Carper, S. Zhang, J. Turk, S. Ramanadham, Skeletal muscle group VIA phospholipase A2 (iPLA2beta): expression and role in fatty acid oxidation, Biochemistry (Mosc.). 47 (2008) 1224112249 .

[28]J.J. Maguire, Y.Y. Tyurina, D. Mohammadyani, A.A. Kapralov, T.S. Anthonymuthu, F. Qu, A.A. Amoscato, L.J. Sparvero, V.A. Tyurin, J. Planas-Iglesias, R.-R. He, J. Klein-Seetharaman, H. Bayır, V.E. Kagan, Known unknowns of cardiolipin signaling: The best is yet to come, Biochim. Biophys. Acta. 1862 (2017) 8-24.

[29]V.A. Fajardo, L. McMeekin, C. Saint, P.J. LeBlanc, Cardiolipin linoleic acid content and mitochondrial cytochrome $\mathrm{c}$ oxidase activity are associated in rat skeletal muscle, Chem. Phys. Lipids. 187 (2015) 50-55.

[30]P.G. Barth, H.R. Scholte, J.A. Berden, J.M. Van der Klei-Van Moorsel, I.E. Luyt-Houwen, E.T. Van 't Veer-Korthof, J.J. Van der Harten, M.A. Sobotka-Plojhar, An X-linked mitochondrial disease affecting cardiac muscle, skeletal muscle and neutrophil leucocytes, J. Neurol. Sci. 62 (1983) 327-355.

[31]C.T. Spencer, B.J. Byrne, R.M. Bryant, R. Margossian, M. Maisenbacher, P. Breitenger, P.B. Benni, S. Redfearn, E. Marcus, W.T. Cade, Impaired cardiac reserve and severely diminished skeletal muscle $\mathrm{O}_{2}$ utilization mediate exercise intolerance in Barth syndrome, Am. J. Physiol. Heart Circ. Physiol. 301 (2011) H2122-2129.

[32]C. Powers, Y. Huang, A. Strauss, Z. Khuchua, Diminished Exercise Capacity and Mitochondrial bc1 Complex Deficiency in Tafazzin-Knockdown Mice, Front. Physiol. 4 (2013) 74. 
[33]G. Wang, M.L. McCain, L. Yang, A. He, F.S. Pasqualini, A. Agarwal, H. Yuan, D. Jiang, D. Zhang, L. Zangi, J. Geva, A.E. Roberts, Q. Ma, J. Ding, J. Chen, D.-Z. Wang, K. Li, J. Wang, R.J.A. Wanders, W. Kulik, F.M. Vaz, M.A. Laflamme, C.E. Murry, K.R. Chien, R.I. Kelley, G.M. Church, K.K. Parker, W.T. Pu, Modeling the mitochondrial cardiomyopathy of Barth syndrome with induced pluripotent stem cell and heart-on-chip technologies, Nat. Med. 20 (2014) 616-623.

[34]F. Gonzalvez, M. D’Aurelio, M. Boutant, A. Moustapha, J.-P. Puech, T. Landes, L. ArnaunéPelloquin, G. Vial, N. Taleux, C. Slomianny, R.J. Wanders, R.H. Houtkooper, P. Bellenguer, I.M. Møller, E. Gottlieb, F.M. Vaz, G. Manfredi, P.X. Petit, Barth syndrome: cellular compensation of mitochondrial dysfunction and apoptosis inhibition due to changes in cardiolipin remodeling linked to tafazzin (TAZ) gene mutation, Biochim. Biophys. Acta. 1832 (2013) 1194-1206.

[35]Y. Xu, C.K.L. Phoon, B. Berno, K. D’Souza, E. Hoedt, G. Zhang, T.A. Neubert, R.M. Epand, M. Ren, M. Schlame, Loss of protein association causes cardiolipin degradation in Barth syndrome, Nat. Chem. Biol. 12 (2016) 641-647.

[36]A. Bashir, K.L. Bohnert, D.N. Reeds, L.R. Peterson, A.J. Bittel, L. de Las Fuentes, C.A. Pacak, B.J. Byrne, W.T. Cade, Impaired cardiac and skeletal muscle bioenergetics in children, adolescents, and young adults with Barth syndrome, Physiol. Rep. 5 (2017).

[37]L. Grobet, D. Pirottin, F. Farnir, D. Poncelet, L.J. Royo, B. Brouwers, E. Christians, D. Desmecht, F. Coignoul, R. Kahn, M. Georges, Modulating skeletal muscle mass by postnatal, musclespecific inactivation of the myostatin gene, Genes. N. Y. N 2000. 35 (2003) 227-238.

[38]A.M. Cogswell, R.J. Stevens, D.A. Hood, Properties of skeletal muscle mitochondria isolated from subsarcolemmal and intermyofibrillar regions, Am. J. Physiol. 264 (1993) C383-389.

[39]J. Folch, M. Lees, G.H. Sloane Stanley, A simple method for the isolation and purification of total lipides from animal tissues, J. Biol. Chem. 226 (1957) 497-509.

[40]C. Coudray, G. Fouret, K. Lambert, C. Ferreri, J. Rieusset, A. Blachnio-Zabielska, J. Lecomte, R. Ebabe Elle, E. Badia, M.P. Murphy, C. Feillet-Coudray, A mitochondrial-targeted ubiquinone modulates muscle lipid profile and improves mitochondrial respiration in obesogenic diet-fed rats, Br. J. Nutr. 115 (2016) 1155-1166.

[41]G. Lepage, C.C. Roy, Specific methylation of plasma nonesterified fatty acids in a one-step reaction, J. Lipid Res. 29 (1988) 227-235.

[42]E. Warensjö, U. Risérus, I.-B. Gustafsson, R. Mohsen, T. Cederholm, B. Vessby, Effects of saturated and unsaturated fatty acids on estimated desaturase activities during a controlled dietary intervention, Nutr. Metab. Cardiovasc. Dis. NMCD. 18 (2008) 683-690.

[43]M. Aoun, G. Fouret, F. Michel, B. Bonafos, J. Ramos, J.-P. Cristol, M.-A. Carbonneau, C. Coudray, C. Feillet-Coudray, Dietary fatty acids modulate liver mitochondrial cardiolipin content 
and its fatty acid composition in rats with non alcoholic fatty liver disease, J. Bioenerg. Biomembr. 44 (2012) 439-452.

[44]G.R. Bartlett, Phosphorus assay in column chromatography, J. Biol. Chem. 234 (1959) 466-468.

[45]G. Fouret, E. Tolika, J. Lecomte, B. Bonafos, M. Aoun, M.P. Murphy, C. Ferreri, C. Chatgilialoglu, E. Dubreucq, C. Coudray, C. Feillet-Coudray, The mitochondrial-targeted antioxidant, MitoQ, increases liver mitochondrial cardiolipin content in obesogenic diet-fed rats, Biochim. Biophys. Acta. 1847 (2015) 1025-1035.

[46]P.A. Srere, An eclectic view of metabolic regulation: control of citrate synthase activity, Adv. Enzyme Regul. 9 (1970) 221-233.

[47]K. Yang, L. Julan, F. Rubio, A. Sharma, H. Guan, Cadmium reduces 11 beta-hydroxysteroid dehydrogenase type 2 activity and expression in human placental trophoblast cells, Am. J. Physiol. Endocrinol. Metab. 290 (2006) E135-E142. doi:10.1152/ajpendo.00356.2005.

[48]T.D. Schmittgen, K.J. Livak, Analyzing real-time PCR data by the comparative C(T) method, Nat. Protoc. 3 (2008) 1101-1108.

[49]G.C. Henderson, M.A. Tuazon, Separation of positional and geometrical fatty acid isomers as 2nitrophenylhydrazide derivatives by high-performance liquid chromatography, Anal. Biochem. 413 (2011) 66-68.

[50]M.A. Tuazon, G.C. Henderson, Fatty acid profile of skeletal muscle phospholipid is altered in mdx mice and is predictive of disease markers, Metabolism. 61 (2012) 801-811.

[51]E. Mouisel, K. Relizani, L. Mille-Hamard, R. Denis, C. Hourdé, O. Agbulut, K. Patel, L. Arandel, S. Morales-Gonzalez, A. Vignaud, L. Garcia, A. Ferry, S. Luquet, V. Billat, R. Ventura-Clapier, M. Schuelke, H. Amthor, Myostatin is a key mediator between energy metabolism and endurance capacity of skeletal muscle, Am. J. Physiol. Regul. Integr. Comp. Physiol. 307 (2014) R444-454.

[52]J.J. Hulmi, B.M. Oliveira, M. Silvennoinen, W.M.H. Hoogaars, A. Pasternack, H. Kainulainen, O. Ritvos, Exercise restores decreased physical activity levels and increases markers of autophagy and oxidative capacity in myostatin/activin-blocked mdx mice, Am. J. Physiol. Endocrinol. Metab. 305 (2013) E171-182.

[53]J.G. Nickerson, H. Alkhateeb, C.R. Benton, J. Lally, J. Nickerson, X.-X. Han, M.H. Wilson, S.S. Jain, L.A. Snook, J.F.C. Glatz, A. Chabowski, J.J.F.P. Luiken, A. Bonen, Greater transport efficiencies of the membrane fatty acid transporters FAT/CD36 and FATP4 compared with FABPpm and FATP1 and differential effects on fatty acid esterification and oxidation in rat skeletal muscle, J. Biol. Chem. 284 (2009) 16522-16530. 
[54]T. Guo, W. Jou, T. Chanturiya, J. Portas, O. Gavrilova, A.C. McPherron, Myostatin inhibition in muscle, but not adipose tissue, decreases fat mass and improves insulin sensitivity, PloS One. 4 (2009) e4937.

[55]L. Teboul, M. Febbraio, D. Gaillard, E.Z. Amri, R. Silverstein, P.A. Grimaldi, Structural and functional characterization of the mouse fatty acid translocase promoter: activation during adipose differentiation, Biochem. J. 360 (2001) 305-312.

[56]H. Guillou, D. Zadravec, P.G.P. Martin, A. Jacobsson, The key roles of elongases and desaturases in mammalian fatty acid metabolism: Insights from transgenic mice, Prog. Lipid Res. 49 (2010) 186-199.

[57]J.C.M. Holthuis, A.K. Menon, Lipid landscapes and pipelines in membrane homeostasis, Nature. $510(2014) 48-57$.

[58]F. Le Borgne, S. Guyot, M. Logerot, L. Beney, P. Gervais, J. Demarquoy, Exploration of lipid metabolism in relation with plasma membrane properties of Duchenne muscular dystrophy cells: influence of L-carnitine, PloS One. 7 (2012) e49346.

[59]G. Paradies, F.M. Ruggiero, Decreased activity of the pyruvate translocator and changes in the lipid composition in heart mitochondria from hypothyroid rats, Arch. Biochem. Biophys. 269 (1989) 595-602.

[60]G. Paradies, G. Petrosillo, F.M. Ruggiero, Cardiolipin-dependent decrease of cytochrome c oxidase activity in heart mitochondria from hypothyroid rats, Biochim. Biophys. Acta. 1319 (1997) 5-8.

[61]G. Paradies, F.M. Ruggiero, P. Dinoi, G. Petrosillo, E. Quagliariello, Decreased cytochrome oxidase activity and changes in phospholipids in heart mitochondria from hypothyroid rats, Arch. Biochem. Biophys. 307 (1993) 91-95.

[62]G. Paradies, F.M. Ruggiero, G. Petrosillo, E. Quagliariello, Alterations in carnitine-acylcarnitine translocase activity and in phospholipid composition in heart mitochondria from hypothyroid rats, Biochim. Biophys. Acta. 1362 (1997) 193-200.

[63]G. Paradies, F.M. Ruggiero, G. Petrosillo, E. Quagliariello, Age-dependent decline in the cytochrome c oxidase activity in rat heart mitochondria: role of cardiolipin, FEBS Lett. 406 (1997) 136-138.

[64]M. Schlame, S. Shanske, S. Doty, T. König, T. Sculco, S. DiMauro, T.J. Blanck, Microanalysis of cardiolipin in small biopsies including skeletal muscle from patients with mitochondrial disease, J. Lipid Res. 40 (1999) 1585-1592.

[65]R.H. Houtkooper, F.M. Vaz, Cardiolipin, the heart of mitochondrial metabolism, Cell. Mol. Life Sci. CMLS. 65 (2008) 2493-2506. 
[66]M. Schlame, M. Ren, The role of cardiolipin in the structural organization of mitochondrial membranes, Biochim. Biophys. Acta. 1788 (2009) 2080-2083.

[67]B. Hoffmann, A. Stöckl, M. Schlame, K. Beyer, M. Klingenberg, The reconstituted ADP/ATP carrier activity has an absolute requirement for cardiolipin as shown in cysteine mutants, J. Biol. Chem. 269 (1994) 1940-1944.

[68]S.M. Claypool, Y. Oktay, P. Boontheung, J.A. Loo, C.M. Koehler, Cardiolipin defines the interactome of the major ADP/ATP carrier protein of the mitochondrial inner membrane, J. Cell Biol. 182 (2008) 937-950.

[69]G.P. Holloway, V.A. Fajardo, L. McMeekin, P.J. LeBlanc, Unsaturation of mitochondrial membrane lipids is related to palmitate oxidation in subsarcolemmal and intermyofibrillar mitochondria, J. Membr. Biol. 245 (2012) 165-176.

[70]L.E. Stefanyk, N. Coverdale, B.D. Roy, S.J. Peters, P.J. LeBlanc, Skeletal muscle type comparison of subsarcolemmal mitochondrial membrane phospholipid fatty acid composition in rat, J. Membr. Biol. 234 (2010) 207-215.

[71]C. Baligand, H. Gilson, J.C. Ménard, O. Schakman, C. Wary, J.-P. Thissen, P.G. Carlier, Functional assessment of skeletal muscle in intact mice lacking myostatin by concurrent NMR imaging and spectroscopy, Gene Ther. 17 (2010) 328-337.

[72]G.D. Barish, V.A. Narkar, R.M. Evans, PPAR delta: a dagger in the heart of the metabolic syndrome, J. Clin. Invest. 116 (2006) 590-597.

[73]Y.-X. Wang, C.-L. Zhang, R.T. Yu, H.K. Cho, M.C. Nelson, C.R. Bayuga-Ocampo, J. Ham, H. Kang, R.M. Evans, Regulation of muscle fiber type and running endurance by PPARdelta, PLoS Biol. 2 (2004) e294.

[74]S. Luquet, J. Lopez-Soriano, D. Holst, A. Fredenrich, J. Melki, M. Rassoulzadegan, P.A. Grimaldi, Peroxisome proliferator-activated receptor delta controls muscle development and oxidative capability, FASEB J. Off. Publ. Fed. Am. Soc. Exp. Biol. 17 (2003) 2299-2301.

[75]Y.Z. Feng, N. Nikolić, S.S. Bakke, M.V. Boekschoten, S. Kersten, E.T. Kase, A.C. Rustan, G.H. Thoresen, PPAR $\delta$ activation in human myotubes increases mitochondrial fatty acid oxidative capacity and reduces glucose utilization by a switch in substrate preference, Arch. Physiol. Biochem. 120 (2014) 12-21.

[76]A.C. McPherron, S.J. Lee, Double muscling in cattle due to mutations in the myostatin gene, Proc. Natl. Acad. Sci. U. S. A. 94 (1997) 12457-12461. 
[77]F. Rahimov, O.D. King, L.C. Warsing, R.E. Powell, C.P. Emerson, L.M. Kunkel, K.R. Wagner, Gene expression profiling of skeletal muscles treated with a soluble activin type IIB receptor, Physiol. Genomics. 43 (2011) 398-407.

[78]C. Feillet-Coudray, G. Fouret, F. Casas, C. Coudray, Impact of high dietary lipid intake and related metabolic disorders on the abundance and acyl composition of the unique mitochondrial phospholipid, cardiolipin, J. Bioenerg. Biomembr. 46 (2014) 447-457.

[79]M.G. Nikolaidis, V. Mougios, Effects of exercise on the fatty-acid composition of blood and tissue lipids, Sports Med. Auckl. NZ. 34 (2004) 1051-1076. 